Review

\title{
Some Aircraft Considered New in 2020
}

\author{
Florian Ion Tiberiu Petrescu
}

ARoTMM-IFToMM, Bucharest Polytechnic University, Bucharest, (CE), Romania

Article history

Received: 13-11-2020

Revised: 17-12-2020

Accepted: 21-12-2020

Email: fitpetrescu@gmail.com

\begin{abstract}
The paper briefly presents some models of aircraft considered avant-garde in 2020 and it is part of the reviews on news in aviation and aerospace. It briefly presents some basic features, news and more important data for each new model on display, so that the reader can get an image of that model but also an overall one, to compare different models from a particular manufacturer with each other, as well as with those belonging to another manufacturer. Aircraft manufacturers are constantly concerned with modifying their aircraft and building other new models that meet customer requirements as much as possible, but at the same time lead to reductions in total fuel consumption used in flight, to reduce pollution due to flights and the negative effects on planetary ecosystems, as well as the increase in the quality and safety of air travel.
\end{abstract}

Keywords: Mach 3, New Aircraft, Concorde, Aerospace, Aircraft, British Airways

\section{Introduction}

The air travel market is growing rapidly, so designers regularly publish concepts for the air transport of the future.

The aerospace giant airbus tested an unmanned flying taxi created within the Vahana project (Fig. 1). The aircraft, called the alpha one, took off for the first time. The climb was low - only $4.9 \mathrm{~m}$ - and alpha one was in the air for only $53 \mathrm{sec}$, after which it landed. However, the aircraft performed all operations independently, in an autonomous manner. The next day, the Vahana project team performed another alpha one takeoff test and was also successful.

It seems that Airbus has launched the project to "democratize private flights" using all the latest technologies, including automatic vision and electric propulsion. Based on this concept, the Vahana team developed alpha one, a single-passenger electric TakeOff and Landing (VTOL) aircraft. The company's ultimate goal is to create a fleet of self-propelled, dronelike passenger drones, which Waymo is set to launch this year, but Airbus is even more ambitious.

However, before this can happen, Airbus must continue to develop its technology and perform more flight tests, after which it can switch to horizontal flight testing.

\section{Lockheed Martin and Aerion}

Among the developers of the various equipped equipment, there is a real battle over those who will first launch a supersonic aircraft that will be widely used and recently, one of Lockheed Martin's biggest producers joined this race with his new supersonic business jet project.
Lockheed Martin is collaborating with Aerion on a new project and the new aircraft will be named AS2 (Fig. 2).

The main innovation in the production of the aircraft will be the design of three engines: Two are located under the wings of the aircraft, the third in the tail. This arrangement will positively affect both the speed and aerodynamics of the future airliner. It is worth noting that Lockheed Martin engineers presented such a design in 2014, but only now has found a worthy application. In addition, the aircraft cabin will be made according to all standards corresponding to the premium segment and the flight from Los Angeles to Sydney, according to the creators, will take only two hours for the aircraft.

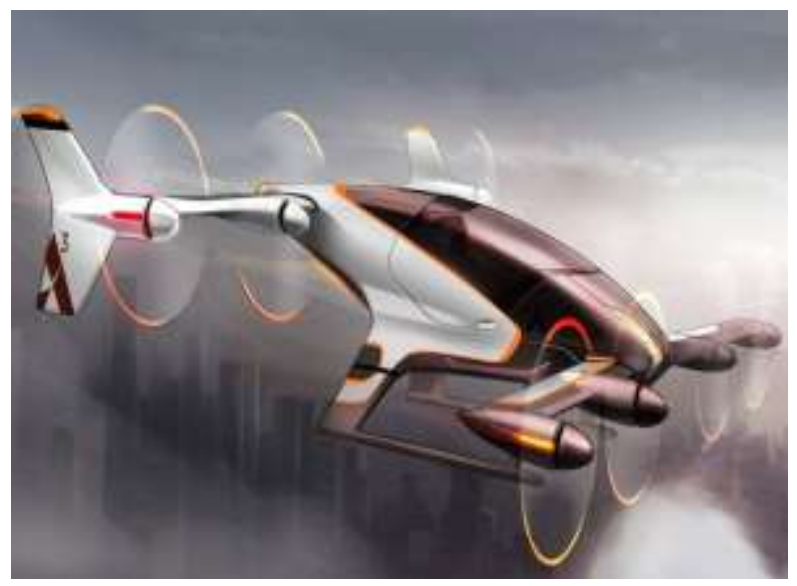

Fig. 1: The aircraft called the alpha one 


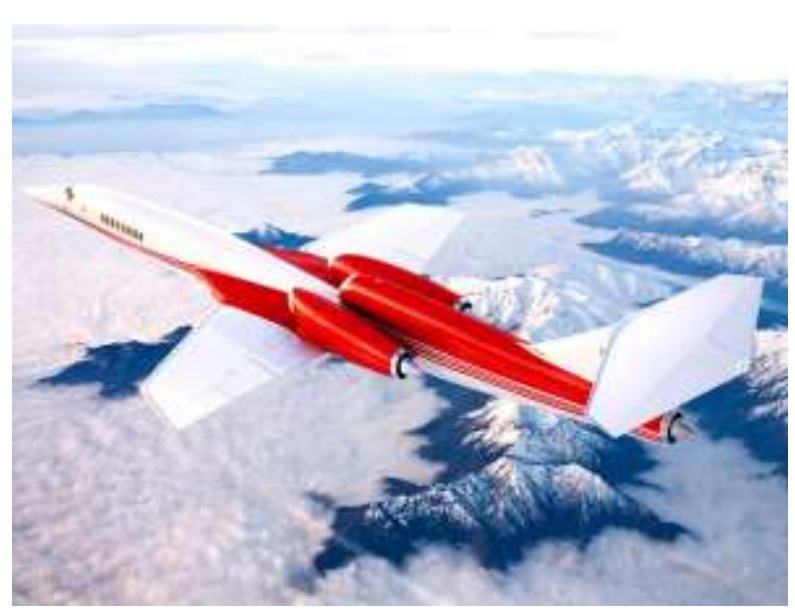

Fig. 2: Lockheed Martin is collaborating with Aerion on a new project and the new aircraft will be named AS2

The collaboration with Aerion was not accidental. The fact is that this company is one of the market leaders in the design of aerodynamic bodies, which is very important for any aircraft.

The founder of the American company SpaceX, Elon Musk, proposed the use of the promising reusable BFR launch vehicles for passenger flights on planet Earth. According to Musk's tweet, due to such missiles, the flight time between any two points on the planet will not exceed one hour. Today, many aircraft designers are working to significantly reduce flight time. The creation of "quiet" supersonic passenger aircraft is considered to be the main way to accelerate air transport. The first such aircraft should appear in the early $2020 \mathrm{~s}$ and will reduce flight time on conventional routes by half on average.

According to a presentation posted on SpaceX's YouTube channel, BFR missiles with passenger modules could be launched from offshore platforms. Passengers will be transported there by high-speed ships. After launching and entering orbit, the detachable stages of the BFR rocket would return to the ground and the passenger module would fly to the target outside the Earth's atmosphere at a speed of 27 thousand kilometers per hour.

Toyota has decided to invest $\$ 350,000$ in a project to create a flying car. According to NHK, this will help complete the development of the vehicle by 2019. The public premiere of the car may take place as early as 2020 at the Tokyo Olympics. According to preliminary data, the flying machine will be called Skydrive (Fig. 3). Several Toyota employees have been working on this project since 2012 on a voluntary basis. The singleseater car will receive four rotors, which will work similarly to modern quadcopters.

The maximum speed of Skydrive will be 100 kilometers per hour. The car will be able to take off at a height of $10 \mathrm{~m}$. The car will also be able to travel on public roads.

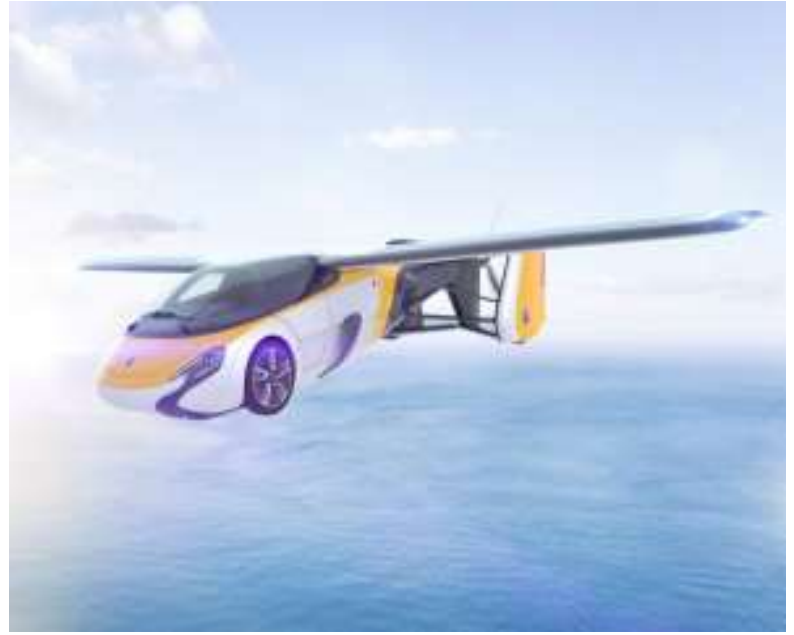

Fig. 3: A Skydrive

Earlier, it was reported that Toyota intends to create a hovercraft. It was assumed that this solution would reduce friction and, consequently, increase engine efficiency and improve control.

At the moment, several companies are engaged in the development of simultaneous flying machines. So, this year such a vehicle was presented by the Slovak company AeroMobil. The development of the car has been going on for 25 years. At this time, the new product is already available for pre-order. Prices for it range from 1.2 to 1.5 million euros.

It takes three minutes for AeroMobil to automatically enter airplane mode.

The power reserve in the ground version is 700 kilometers and in the air version - 750 .

The maximum speed of the car is 160 kilometers per hour. At the same time, in air mode, this figure reaches 360 kilometers per hour. A vehicle can accelerate to 100 kilometers per hour in $10 \mathrm{sec}$. The weight of the car is 960 kilograms.

British billionaire Richard Branson supported the American company Boom in developing a supersonic passenger plane. The day before, the company unveiled a prototype of this aircraft, dubbed the XB-1 Supersonic Demonstrator (Fig 4).

Virgin Galactic from Branson provides financial and technical support for the project. The first test flight of the plane is scheduled for the end of next year, with tests taking place in Southern California.

The prototype presented is a reduced 1: 3 copy of the production model. The aircraft is made of special composite materials, has only 40 standard seats for firstclass passengers, which are arranged one by one.

The new supersonic passenger aircraft is expected to cover the distance between London and New York in 3.5 $\mathrm{h}$, the journey from San Francisco to Tokyo in four hours and from Los Angeles to Sydney in six hours. 


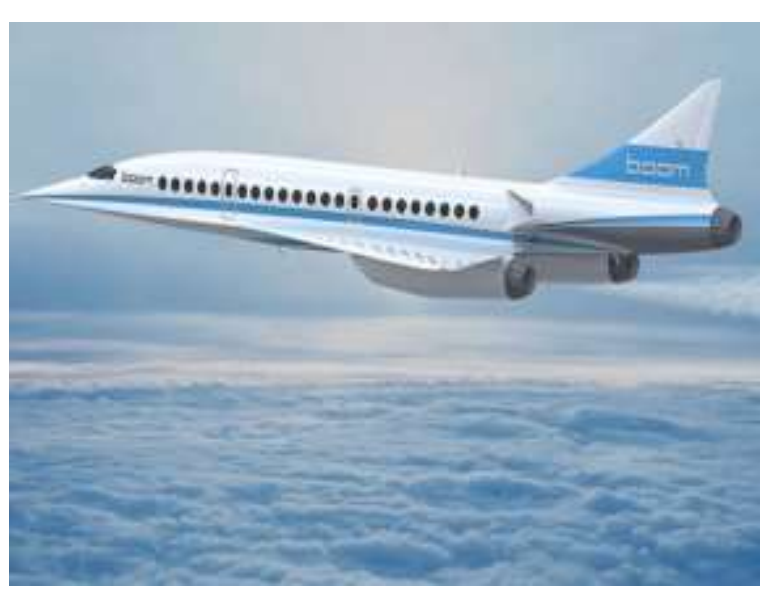

Fig. 4: XB-1 supersonic demonstrator

"I have long been passionate about aerospace innovation and the development of high-speed commercial flights. Virgin Galactic is a space innovator and it was easy for them to decide to work with Boom," says Richard Branson.

The innovative core of the world-class domestic aviation industry will be formed at Zhukovsky. This was stated by Russian Prime Minister Vladimir Putin on the MAKS-2011 air show that is taking place these days. It is assumed that this center will include offices and institutes of scientific design, as well as experimental plants.

Russian authorities expect to set up a world-class research and production group of the domestic aviation industry based on the Zhukovsky National Aircraft Manufacturing Center, Russian Prime Minister Vladimir Putin said at the opening ceremony of the 10th International Motor Show of Aviation and Space MAKS-2011.

"Here in Zhukovsky, our National Aircraft Manufacturing Center is being created, which will include offices and scientific design institutes, experimental plants. In fact, based on the center, an innovative core of the domestic aviation industry will be formed, as we expect - global research and production group ", - Putin said.

"Modest steps have already been taken in this direction: The road has been built, two bridges - this is the beginning," the prime minister stressed.

Keep in mind that transportation logistics is a big issue for Zhukovsky. Participants in the air show complain that it is quite problematic to get to the venue.

The Prime Minister expressed his hope that "until the next air show, MAKS-2013, the building of the new headquarters of the United Aviation Corporation, as well as other facilities of the National Aircraft Construction Center, will appear here."

Referring to the issue of modernization, Vladimir Putin mentioned that the Russian authorities will continue to support the Russian aerospace complex, which is a strategic priority for the country.

"The state has offered and will continue to provide support to the Russian aerospace complex. This is an absolutely strategic priority for us," Putin said.

According to him, only in 2009 - in 2011, more than 270 billion rubles were allocated for the development of the aviation industry.

"After the level of annual spending on space exploration, the country has become the fourth in the world in terms of absolute volumes of investment," added the Prime Minister.

He noted that even in times of crisis, it was possible to ensure the promotion of all key projects with which the future of astronautics is connected, as well as civil and military aviation.

Putin said that Russia is returning to research programs for the planets of the solar system, increasing the Russian orbital constellation, including satellites of the GLONASS system.

"We are actively working on the MC-21 aircraft project; this is a mid-range aircraft with a composite wing, as well as promising Mi-38 and Ka-62 helicopters. The series production of the Russian-Ukrainian an-148 aircraft was launched in various modifications", - said the head of the government.

According to him, the consolidation of the aeronautical industry has been completed all enterprises and facilities that are part of the integrated structures have clear development prospects (The highlight of the second day of MAKS-2011 which was attended by Vladimir Putin, the oldest Russian fighter aircraft of the fifth-generation T-50 PAK FA).

It is assumed that the helicopters that the airline will receive under the contract will be engaged in meeting the needs of the oil and gas industry, performing flights related to installation and firefighting works and will also be operated under the contracts with the UN and abroad.

Dmitry Petrov, head of Russian Helicopters, noted that the airline is "the largest civilian customer of helicopter technology." There are now more than 50 Mi-171 s in the UTair fleet.

In addition, the Russian helicopter holding and Gazpromavia signed on Wednesday on the air show MAKS-2011 in the presence of Russian Prime Minister Vladimir Putin a general agreement on the supply of 39 Mi-8AMT helicopters.

UTair Aviation also pleased Sukhoi Civil Aircraft with a contract to supply 24 Sukhoi SuperJet-100 aircraft under a leasing system. The total value of the transaction is 760.8 million USD in catalog prices, Interfax reports.

At the MAKS-2011 air show, Sukhoi Civil Aircraft also entered into an agreement with Gazpromkomplektatsiya for the supply of 10 Sukhoi SuperJet-100/95LR aircraft to Gazpromavia. The transaction is valued at $\$ 323$ million 
at current catalog prices. The delivery of the linings is scheduled for the period 2013-2015.

During the MAKS-2011 air show, the Ukrainian state-owned enterprise Antonov received a certificate for the production of Russian-Ukrainian regional passenger aircraft of the new generation an-158.

34 Ukrainian companies, 169 Russian companies and other companies from 13 countries were engaged in the development and construction of the an-158 aircraft.

An-158 is a modification of the an-148 short-haul passenger aircraft. Compared to its predecessor, it has increased the number of passenger seats (up to 99), extended the passenger cabin, increased the volume of luggage racks and reduced fuel consumption and operating costs. The flight range with the maximum number of passengers is 2.5 thousand kilometers.

For more than a year (it took off on March 9, 2015) the trip around the world "has ended", you might think that the development of passenger aviation has stopped or even going in the opposite direction. Of course, Solar Impulse 2 is not the future of aviation, but modern aircraft are slower than the supersonic Concorde flew 30 years ago. The new aircraft models generally differ from the old ones only in terms of higher fuel consumption. Airbus will not even develop a new aircraft by 2020 . However, things are not so hopeless. The most promising projects in the field of aeronautics are described below, demonstrating that the development of aviation continues (Anderson, 1997; CE, 2018; García, 2020; Rana, 2020; Garfo et al., 2020; Kumar and Sreenivasulu, 2019; Mishra and Sarawagi, 2020; Welabo and Tesfamariamr, 2020; Antonescu and Petrescu, 1985; 1989; Antonescu et al., 1985a; 1985b; 1986; 1987; 1988; 1994; 1997; 2000a; 2000b; 2001; Aversa et al., 2017a; 2017b; 2017c; 2017d; 2016a; 2016b; 2016c; 2016d; Ayiei, 2020; Brewer, 1991; Chilukuri et al., 2019; Cao et al., 2013; Dong et al., 2013; Saheed et al., 2019; Riman, 2019; Matthews and Yi, 2019; Dwivedi et al., 2019a; 2019b; Eremia, 2020; Franklin, 1930; Hanrahan, 2014; He et al., 2013; Hertel, 2017; Komakula, 2019; Langston, 2015; 2016; Lee, 2013; Lin et al., 2013; Liu et al., 2013; Padula and Perdereau, 2013; Perumaal and Jawahar, 2013; Petrescu, 2011; 2012; 2019a-v; 2020a-g; Petrescu and Petrescu, 2019a-f; 1995a-b; 1997a-c; 2000a-b; 2002a-b; 2003; 2005a-e; 2011a-c; 2012a-b; 2013a-e; 2014a-h; 2016a-c; 2020; Petrescu et al., 2007; 2009; 2016; 2017a-ak; 2018a-w; 2020; Petrescu and Calautit, 2016a-b; Dekkata and Yi, 2019; Fahim et al., 2019; El Hassouni et al., 2019; Riman, 2018; Nacy and Nayif, 2018; Kortam et al., 2018; Welch and Mondal, 2019; Eissa et al., 2019; Younes et al., 2019; Svensson et al., 2004; Rahman, 2018; Richmond, 2013; Kisabo et al., 2019a; 2019b; Kisabo and Adebimpe, 2019; Kosambe, 2019a-d; Sharma and Kosambe, 2020; Oni and Jha, 2019; Chaudhary and Kumar, 2019; de Lima et al., 2019; Babu et al., 2019; 2020; de Mota
Siqueira et al., 2020; Tumino, 2020; Mishra, 2020a; 2020b; Brischetto and Torre, 2020; Vladescu, 2020).

\section{Materials and Methods}

Airbus is testing a small but completely electric Airbus-E-Fan. The last achievement of the plane is the flight over the English Channel (Fig. 5). To date, this model cannot be used for long flights, not even by a single person.

The problem with electric planes that also carry passengers is that they do not have enough energy to keep the aircraft in the air with a large mass (high load) and even less will they be able to reach high speeds and obviously no acceleration sufficient for important or emergency maneuvers, so the safety of traffic on such aircraft is called into question.

But many aircraft manufacturers have no doubt that the future belongs to electric aviation, or at least they want it, being an important goal, even an international directive. For a start, it is planned, as in cars, to make a hybrid engine. Airbus intends to test a "more electric aircraft" as part of the DISPERSAL project in 2022. The contribution of the electric fan motor to the total force should be $23 \%$.

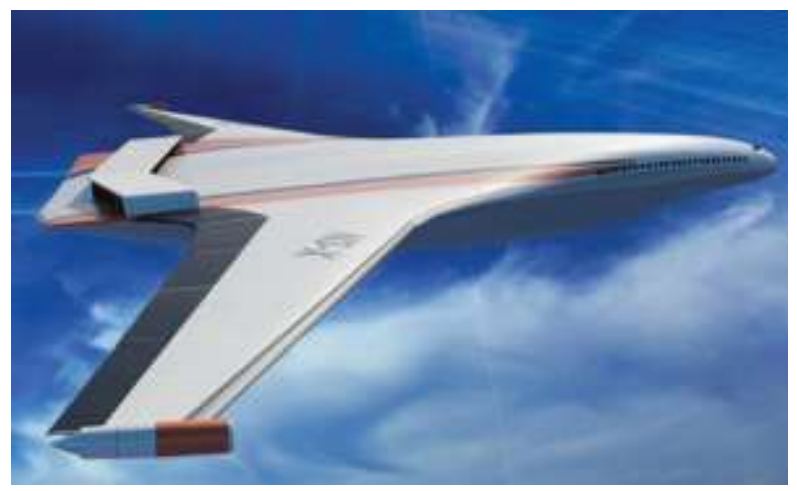

Fig. 5: Airbus is testing a small but completely electric Airbus-E-Fan

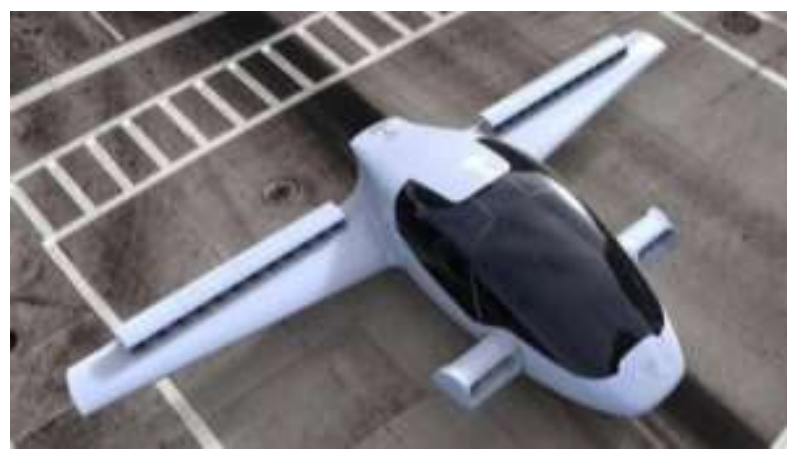

Fig. 6: NASA in 2016 announced the beginning of the development of the X-57 Maxwell aircraft equipped with 14 electric motors 
NASA in 2016 announced the beginning of the development of the X-57 Maxwell aircraft equipped with 14 electric motors. It will be a small four-seater plane (Fig. 6).

According to engineers, the introduction of electric motors will significantly reduce operating costs. The agency does not report when the aircraft will be created.

German startup Lilium Aviation has received funding to build a private electric jet capable of taking off and landing without an airport. For takeoff and landing, the plane will need only $225 \mathrm{~m}$. The company has already built a prototype and intends to unveil a full-size version at the end of 2018. The Boeing 737 MAX has already received 2,500 orders and could become a market leader (Fig. 7).

The declared superiority over the existing Airbus A320neo leader is that it uses $4 \%$ less fuel. The first deliveries to customers will begin in 2017. Too bad that this super company has recently had image failures due to technical problems repeatedly reported on at least one basic model. The Boeing 737 MAX approached the time when it would resume commercial flights on Tuesday, with the help of the United States Aviation Administration (FAA), which said it would soon accept a proposal to re-authorize the aircraft, according to AFP.

The aircraft completed a series of certification flights in early July, a crucial step in its return to service, as civil aviation authorities cannot approve the modified version of the aircraft until they have examined its behavior in the air.

The Agency now intends to publish an "airworthiness" notice "in the near future".

"In line with our commitment to remain transparent, we will allow the public for 45 days to comment on the proposed changes to alleviate the safety issues identified in the investigations following the Lion Air and Ethiopian Airlines accidents," the FAA added.

The 737 MAX was banned from a flight on March 13, 2019, after the crash of an Ethiopian Airlines model that killed 157 people. The tragedy came just a few months after the disaster aboard a Lion Air MAX, which killed 189 people.

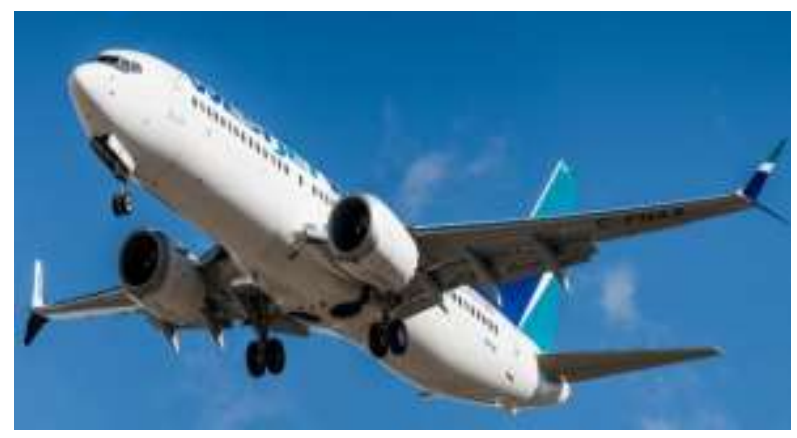

Fig. 7: The Boeing 737 MAX
The FAA, whether or not it needs to give the green light to return to 737 MAX service, ensures "continuing a robust certification process." In January, Boeing did not receive any new orders for aircraft, being the first time such a thing had happened in January 1962 and until now, given that the once best-selling aircraft, the 737 MAX, remains listed at the ground after two serious accidents, the Reuters reports.

As of March 2019, Boeing 737 MAX aircraft, the best-selling model of the American manufacturer, have been banned from flying worldwide after two air disasters that occurred within five months and in which a malfunction of the aircraft was suspected. The automatic flight stabilization system (MCAS) intended to prevent the airplane from entering the dive. The US aviation group hopes its aircraft will return to service by the end of 2019, following changes to software systems and pilot training programs, but in early December 2019, the Federal Aviation Administration (FAA) announced that it would not approve the resumption of 737 MAX aircraft flights before 2020 .

The crisis caused by the 737 MAX forced Boeing to stop the production of its best-selling aircraft and change its general manager at the end of December.

Boeing's new long-haul aircraft, 777X, makes its first test flight on Saturday, taking off from Paine Airfield, near Everett, in the northeastern United States, reports AFP (Fig. 8).

According to Boeing officials, this inaugural flight will last 3-5 $\mathrm{h}$ and marks the start of a whole series of flight tests leading to the certification of the aircraft, before it enters service in 2021 . The $777 \mathrm{X}$, which can carry between 384 and 426 passengers, already has orders for 340 units, mainly from seven major airlines, including Emirates, Lufthansa, Cathay Pacific, Singapore Airlines and Qatar Airways. The machine encountered significant problems during its September pressurization tests.

The 8-passenger Bombardier Global 8000 business jet will be able to fly a record 14,600 kilometers without refueling at an average speed of $956 \mathrm{~km} / \mathrm{h}$ (Fig. 9).

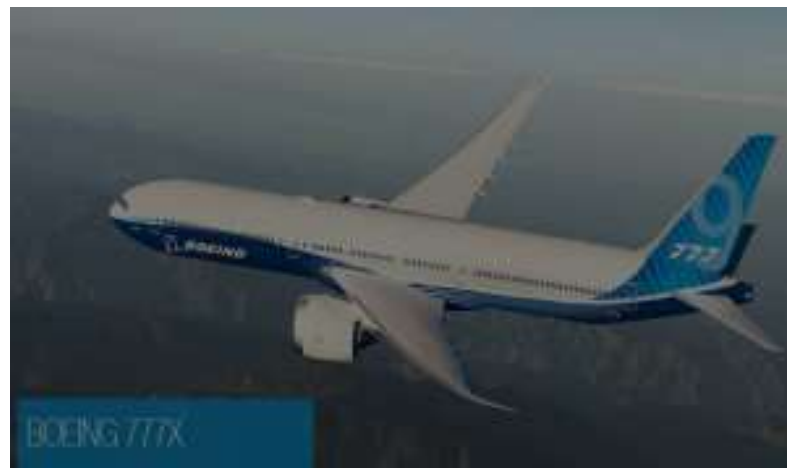

Fig. 8: The Boeing 777X 
The company wants to start sales in 2019 at a price of about 65 million dollars. Gulfstream G600, new business aircraft that will be put on sale in 2018-2020, will also compete with the aircraft. The planes will cost from $\$ 35$ million to $\$ 55$ million.

The new private jet, the Cobalt Co50 Valkyrie (Fig. 10), is cheaper than the competition $(\$ 600,000)$ and is the fastest in its class, but its main design innovation is that it looks exactly like Bruce Wayne's plane. It can carry up to 5 passengers at a time.

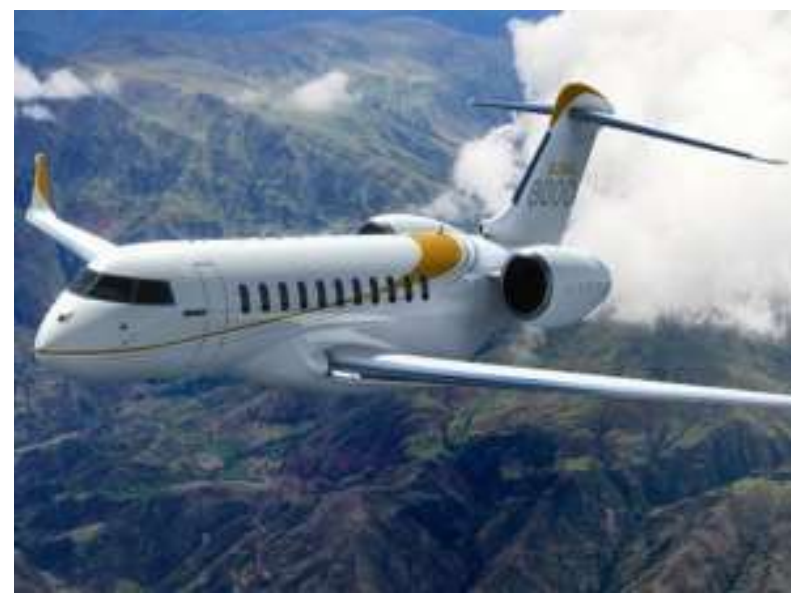

Fig. 9: Bombardier Global 8000

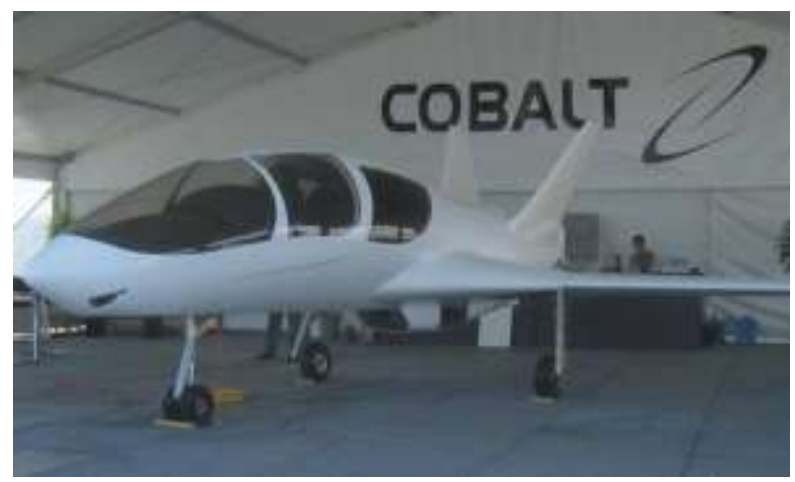

Fig. 10: The new private jet, the Cobalt Co50 Valkyrie

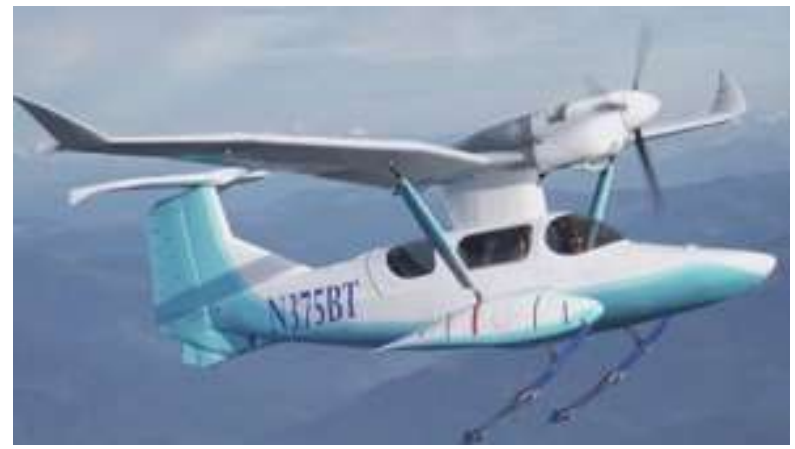

Fig. 11: The private SkiGull amphibious aircraft
The private SkiGull amphibious aircraft (Fig. 11) will be able to land not only on water but in general on any surface (grass, snow, ice). It made its first flight in November 2015 and will be on sale soon.

The SkiGull is a two-seater composite/titanium aircraft equipped with a retractable ski train that can have wheels attached for operations on water, snow, or land, landing on an area of about $400 \mathrm{~m}$, but with a range to cross oceans. The engine is configured to run on Swift fuel, for car or boat. The aircraft is privately developed.

The public presentation of the SkiGull design was made at the EAA Airventure Convention in 2015. Details include the ability to operate in ocean waves with skis or land on smooth water or grass with retracted skis, cruising speed of 140 knots (optional turbocharger 177 knots), quiet flight, 460-foot water take-off, 47-foot longwing (foldable), trailer-free ground transportation, a $44 \%$ long Fowler flap behind the main propeller and two foldable front-facing electric motors reversible propellers simplify docking and provide optional take-off power.

Another seaplane, the two-seater Icon A5, is capable of taking off and landing on water and can also come out of a spin and is equipped with a parachute for the entire aircraft (Fig. 12).

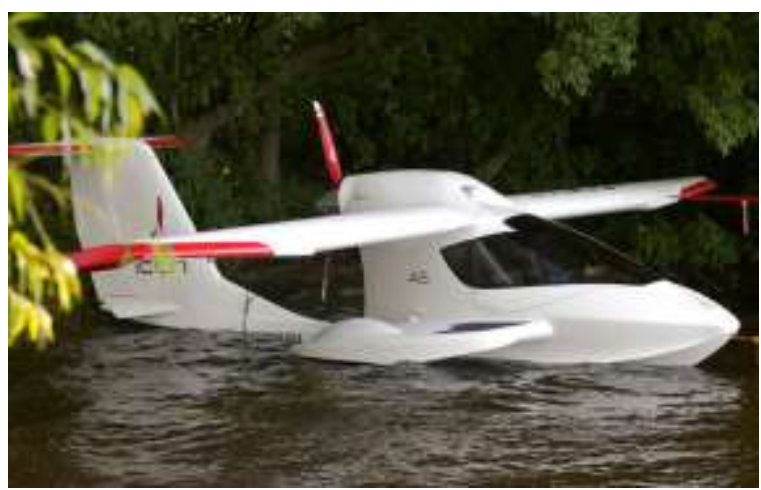

Fig. 12: The two-seater Icon A5

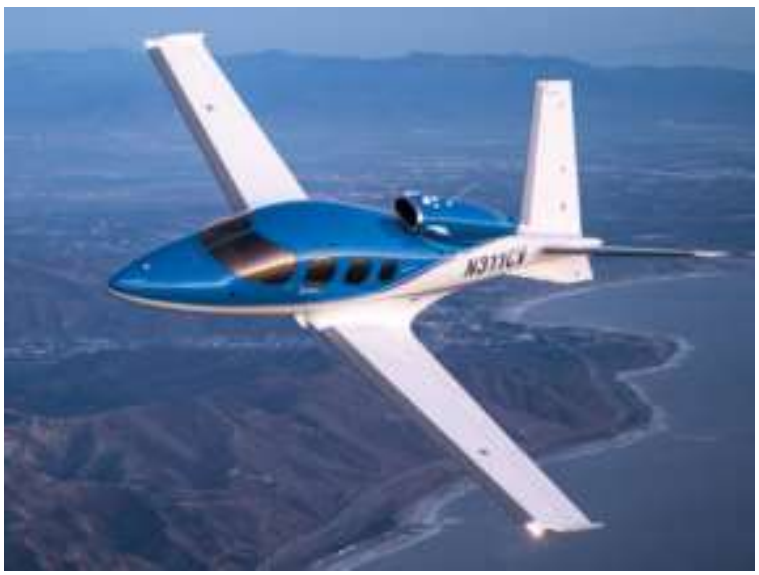

Fig. 13: The Cirrus Vision SF50 business aircraft 
It is recognized as so safe that you do not even need a pilot's license to obtain a flight permit, $20 \mathrm{~h}$ of training are enough. It costs $\$ 250,000$ and is already in production. In 2016, the first 7 pieces were assembled, but 1,850 orders had already been placed for the plane.

The Cirrus Vision SF50 business aircraft is without a doubt the first mass-produced personal aircraft (Fig. 13). It will be able to carry up to 7 passengers and should be much easier to fly than a regular private jet.

It will also have a parachute for the entire plane. 4 prototypes were built and the first aircraft was delivered to the customer in June 2016. In total, over 600 of these cars have already been ordered at a price of 2 million dollars.

The single-seater British e-Go jet is unique for its low price of only $\$ 70,000$, cheaper than many cars (Fig. 14).

The first buyer received the plane in June 2016. A British company has designed and flown a new airplane, the e-Go, powered by a Rotron Wankel rotary engine. The design fits into the Single Seat De-Regulated class, established by the UK in 2007, which is similar to the U.S. ultralight class. The e-Go flew for the first time last week completing several test flights and a demo flight for supporters and the press. With a top speed of 135 knots, the airplane is too fast to qualify as an ultralight in the U.S., but the developers are taking deposits for copies in the UK. It sells for about $\$ 80,000$. They also plan to develop an experimental kit version and an LSA for the U.S. market. "We set out to design a fun flying machine," company founder Tony Bishop told the BBC. "It's lighter and faster and more fun to fly, we think than anything that's out there.

Officially, the Italian company AgustaWestland with the AW609 tiltrotor came closest to the creation of the VTOL transport (Fig. 15). It is indeed capable of landing vertically and flying farther than conventional helicopters, but its speed $(509 \mathrm{~km} / \mathrm{h})$ is still significantly lower than aircraft. Until now, the tiltrotor has been produced only for the needs of the US military. But the AW609 will be civilian transportation for businessmen and the oil industry. Certification is expected in 2017 and 70 orders have already been received.

BA609 was based on the experience gained by Bell's previous experimental tiltrotor, XV-15. In 1996, Bell and Boeing formed a partnership to develop a civilian landing plane; however, in March 1998, it was announced that Boeing had abandoned the project. In September 1998, it was announced that Agusta had become a partner in the development program. This led to the establishment of Bell/Agusta Aerospace (BAAC), a joint venture between Bell Helicopter and AgustaWestland, to develop and manufacture the aircraft. The Italian Government has subsidized the development by Agusta of a military tiltrotor and, given that the AW609 has civil problems, the European Commission is asking AgustaWestland to reimburse the progressive sums per aircraft to the Italian state in order to avoid distortions of competition. Since 2015, Bell has continued to perform contract work on the AW609 program, given the commercial potential for a larger V-280 tiltrotor, where military production can reach a higher number and therefore reduce the unit cost.

The purpose of the plane is to take off and land vertically, but to fly faster than a helicopter. More than 45 different aircraft flew proving the capabilities of VTOL and STOL, of which V-22, Harrier "jump jump", Yakovlev Yak-38 and Lockheed Martin F-35 Lightning II went into production. Until 2008, Bell estimated that very light aircraft and large offshore helicopters, such as the Sikorsky S-92, reduced the potential rotor market. Also in 2008, limited funding for the program by Bell and AgustaWestland was reported to have led to slow progress in flight testing. On September 21, 2009, AgustaWestland CEO Giuseppe Orsi said that parent company Finmeccanica authorized Bell Helicopter to buy the program to speed it up because Bell was unhappy with the business outlook and wanted to spend resources on other programs.

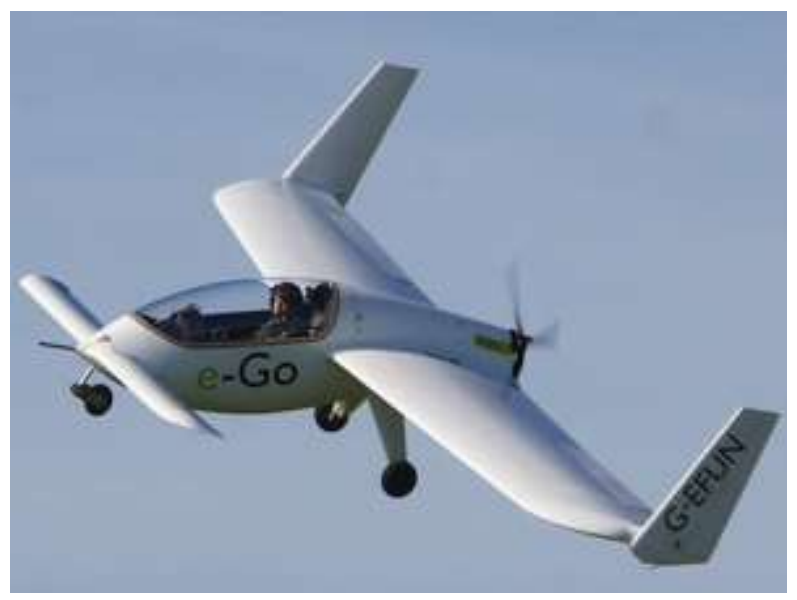

Fig. 14: The single-seater British e-Go jet is unique for its low price of only $\$ 70,000$, cheaper than many cars

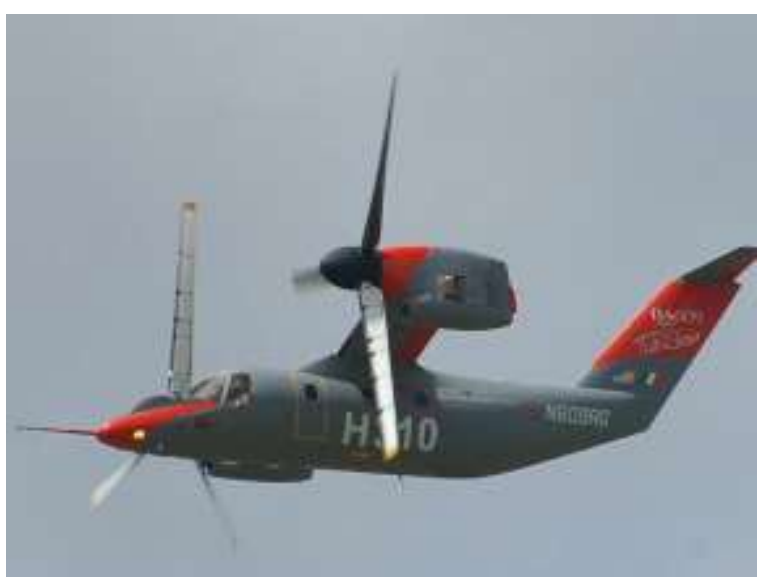

Fig. 15: The AW609 tiltrotor came closest to the creation of the VTOL transport 
In 2013, AgustaWestland estimated a market of 700 aircraft over 20 years. Until 2011, negotiations focused on the full transfer of shared technologies with the V-22, however, Bell said no technology was shared with the V-22. At the 2011 Paris Air Show, AgustaWestland said it would take full ownership of the program, redesignating the aircraft as the "AW609" and that the Bell helicopter would remain in the role of component design and certification. In November 2011, the exchange of ownership was completed, following regulatory approval - the media estimated that the transfer took place at a low cost.

The first ground tests of the BA609 prototype began on December 6, 2002 and the first flight took place on March 6, 2003, in Arlington, Texas, piloted by test pilots Roy Hopkins and Dwayne Williams. After $14 \mathrm{~h}$ of testing the helicopter flight, the prototype was moved to a ground test platform to study the operational effects of the conversion modes.

After the completion of the ground tests on June 3, 2005 , the prototype resumed the flight tests, focusing on the expansion of its flight tire. On July 22, 2005, the first conversion from a helicopter to airplane mode took place during the flight. Since October 2008, two prototype hours have recorded 365 flight hours. The AW609 demonstrated safe double engine failure in normal cruising flight on 15 May 2009. By February 2012, it had increased to $650 \mathrm{~h}$ and it was reported that $85 \%$ of the AW609's flight tire had been explored. Test pilot Paul Edwards said the AW609 was not susceptible to vortex ring state phenomena, naturally slipping only from the vortex, as both rotors will not simultaneously enter the vortex ring state.

In 2011, AgustaWestland began construction of a third prototype; that prototype was not yet fully assembled by February 2015. The company plans to conduct test flights in Italy in the summer of 2015. Agusta Westland then planned to disassemble it and send it to Philadelphia, Pennsylvania, to prepare it for testing thaw from Minnesota.

A fourth prototype, which will be used for the development and testing of new control and avionics systems, was also underway. By November 2012, the two operational prototypes had accumulated over 700 flight hours. In January 2014, it was reported that the two prototypes had accumulated over 850 flight hours; the accumulated flight data are used to further develop representative simulators, which in turn are used to support the development program.

The AW609 is a tiltrotor aircraft capable of landing vertically, while conventional fixed-wing aircraft cannot, allowing the type to serve locations such as heliports or very small airports while having the speed and range of any helicopter available. AgustaWestland promotes the type as "... combining the benefits of a helicopter and a fixed-wing aircraft into a single aircraft".
The AW609 appears to be similar in the exterior to the Army-oriented V-22 Osprey; however, the two aircraft have several components. Unlike the V-22, the AW609 has a pressurized cabin. Since 2013, several cabin configurations have been designed, including a standard nine-passenger structure, a six- to sevenpassenger VIP/executive cabin and a hoist/basket search and rescue model and four single seats; medevacoriented and patrol/surveillance variants have also been proposed. For increased passenger comfort, the cabin is both pressurized and equipped with sound insulation. Access to the cabin is through a two-piece door in the building, 35 inches $(89 \mathrm{~cm})$ wide, fixed centrally in the fuselage under the wings (Fig. 16).

DARPA announced a competition to finally create a vertical take-off aircraft (Fig. 17) and 4 large corporations (Boeing, Aurora Flight Sciences Corp, Sikorsky Aircraft Co and Karem Aircraft) presented their full-size prototypes for testing in February 2017 (Council of the European Union, Policies. 2018).

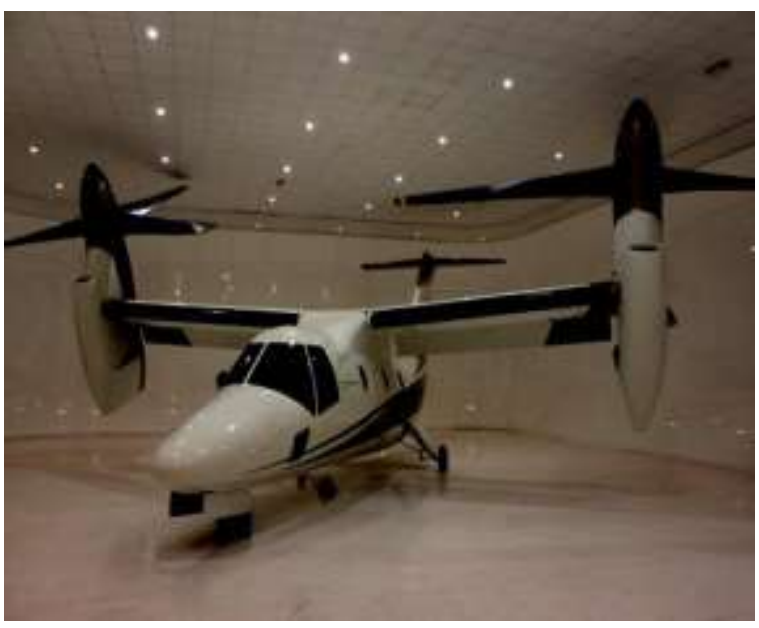

Fig. 16: The AW609

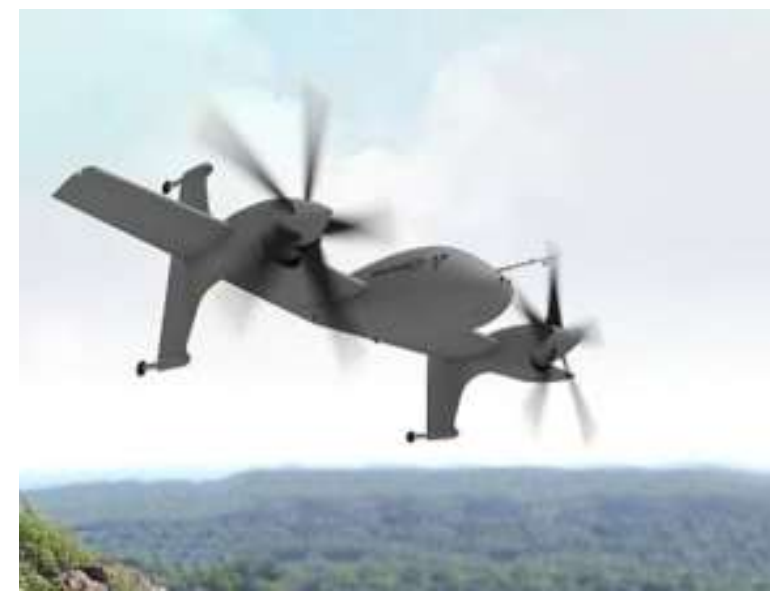

Fig. 17: The Sikorsky moves forward with DARPA VTOL XPlane project to design new military tiltrotor aircraft 


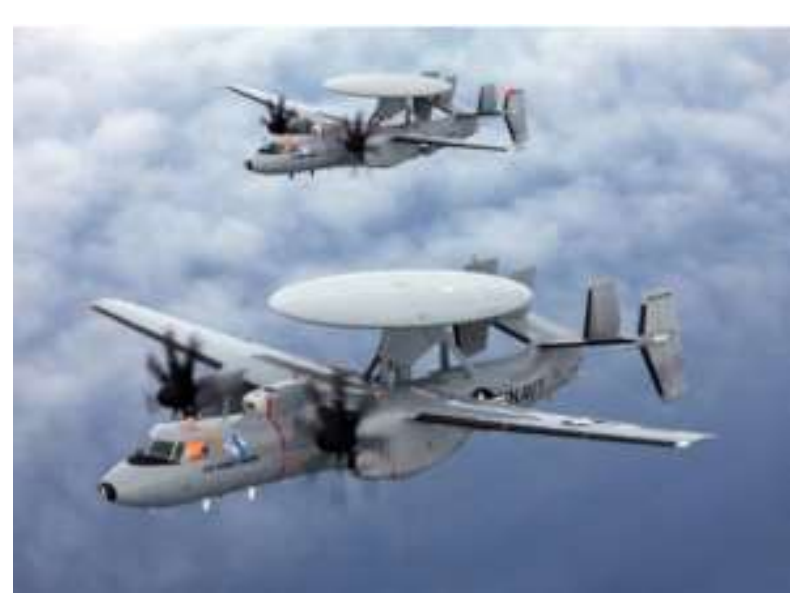

Fig. 18: Northrop Grumman upgrade E-2D flight computers to accommodate teaming among manned and unmanned aircraft

Northrop Grumman upgrade E-2D flight computers to accommodate teaming among manned and unmanned aircraft. MUM-T involves standard computer architecture and communications protocol to share live and still, images gathered from UAV sensor payloads (Fig. 18).

Companies building sixth-generation Tempest fighter jets in the UK have unveiled some of the technological concepts they will incorporate, including a radar system designed to handle as much data per second as a city. Developing for the Royal Air Force (RAF), Tempest will be one of the first fighters of the sixth generation. It is designed to complement current combat craft, such as the F-35 Lightning II and Typhoon fighters, from the mid-2030 s until older warplanes are withdrawn in the 2040 s. The stealth fighter will be able to carry hypersonic missiles and control drone swarms as well as produce large amounts of electricity, allowing it to power laser weapons.

Along with this, the Delta Tempest twin-engine wing will have reconfigurable artificial intelligence and cybernetically enhanced communications, which allow it to act as a flying command and control center, where the pilot acts more as an executive officer than as a dogfighter (Fig. 19).

U.S. military researchers are asking Artificial Intelligence (AI) experts at PhysicsAI in Pacifica, Calif., to develop AI algorithms to enable future experimental high-performance unmanned combat aircraft to formulate teams of manned and unmanned jet fighters (Fig. 19 and 20).

Officials of the U.S. Defense Advanced Research Projects Agency (DARPA) in Arlington, Va., announced a \$2.3 million contract to PhysicsAI earlier this month for the Air Combat Evolution (ACE) Technical Area 1: Build Combat Autonomy project.

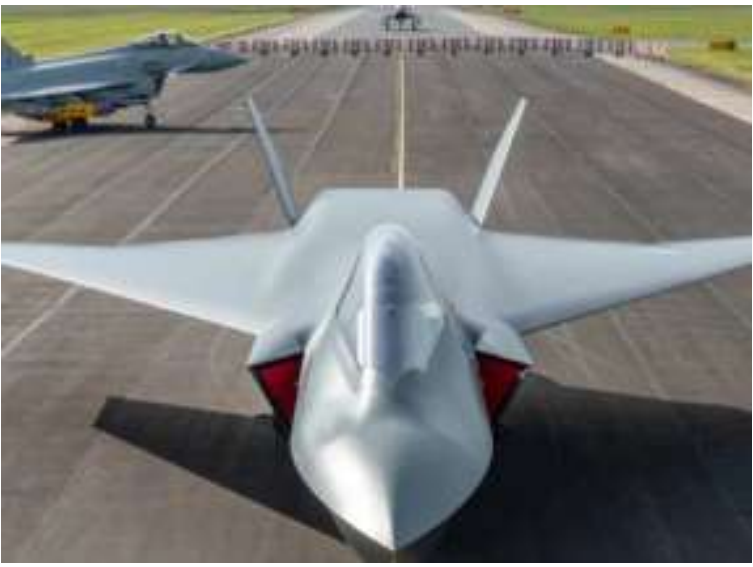

Fig. 19: Tempest sixth-generation jet fighter will have highspeed radar, Artificial Intelligence (AI)

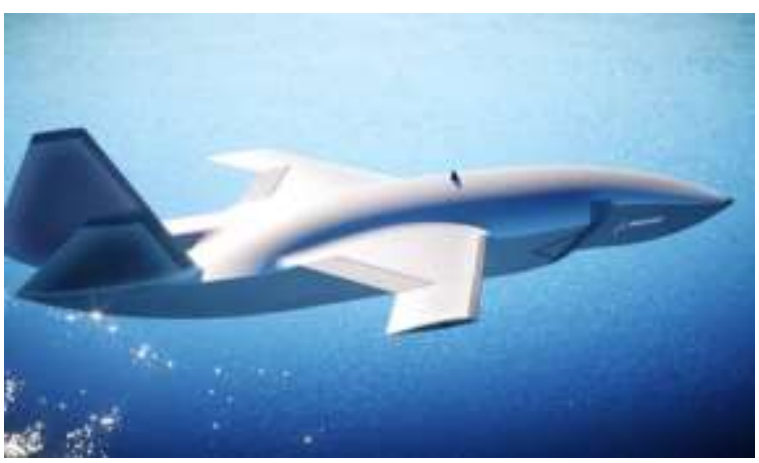

Fig. 20: Physical to develop Artificial Intelligence (AI) algorithms for high-performance unmanned combat aircraft

This project seeks to increase warfighter trust in combat autonomy by automating aerial within-visualrange maneuvering using realistic aircraft.

\section{Results}

Airbus wants to become carbon neutral by 2035 .

Thus, a design is designed to carry up to two hundred passengers with a range of two thousand nautical miles.

The project includes a hydrogen turbofan, which is rotated by a modified gas turbine engine. Liquid hydrogen would be stored and distributed in tanks at the rear of the aircraft (Fig. 21).

The second design, which can carry up to a hundred passengers, uses a turboprop engine, which also runs on hydrogen. It is intended for short-distance travel, covering about a thousand nautical miles. Finally, a third model, the largest of the three, is designed to accommodate two hundred passengers. The concept combines the wings with the main body, creating a massive open space. "The extremely wide fuselage opens up multiple options for hydrogen storage and distribution and for cabin layout," an Airbus statement said. 


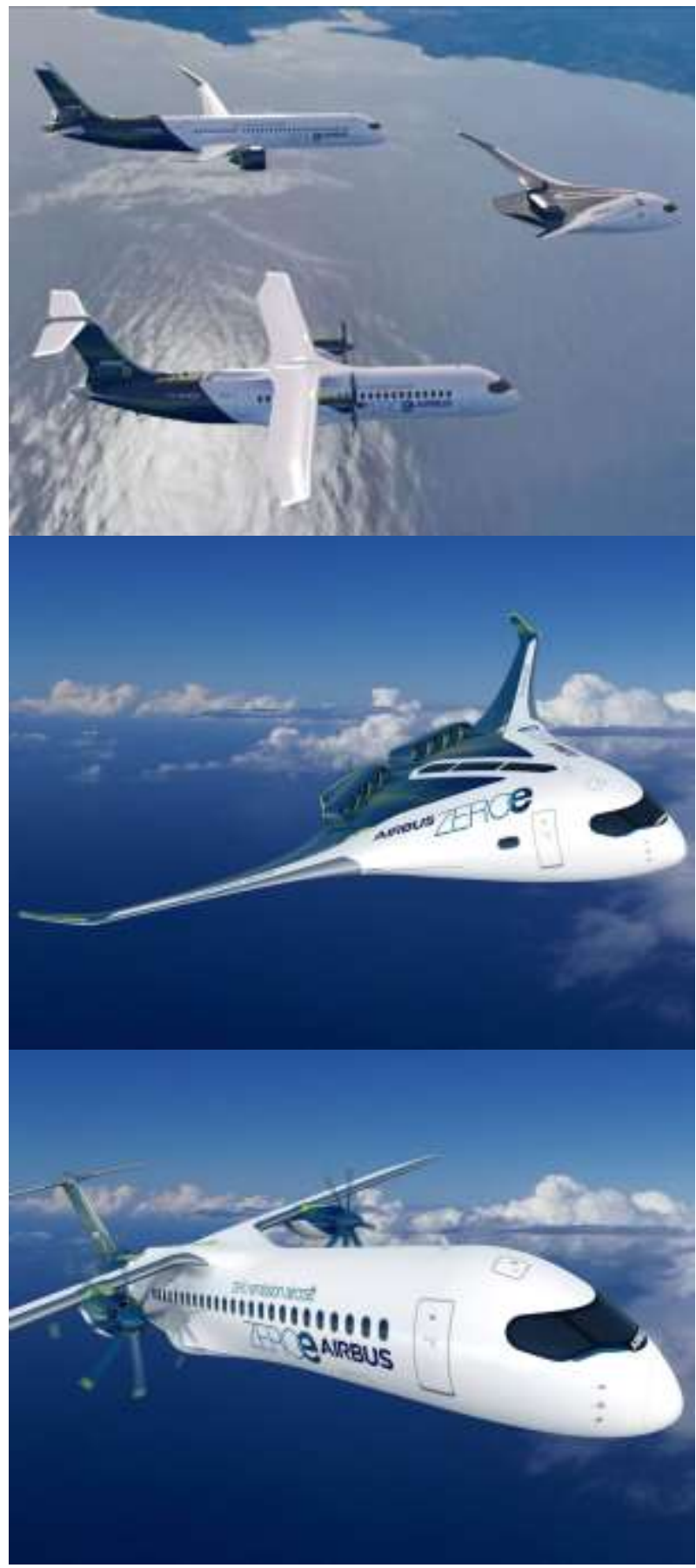

Fig. 21: The project includes a hydrogen turbofan, which is rotated by a modified gas turbine engine

Airbus hopes to spark enthusiasm with these launches around the idea of powering tomorrow's aircraft using hydrogen gas. "The transition to hydrogen, as the primary source of energy for these concept aircraft, will require decisive action from the entire air ecosystem," said Guillaume Faury, CEO of Airbus.

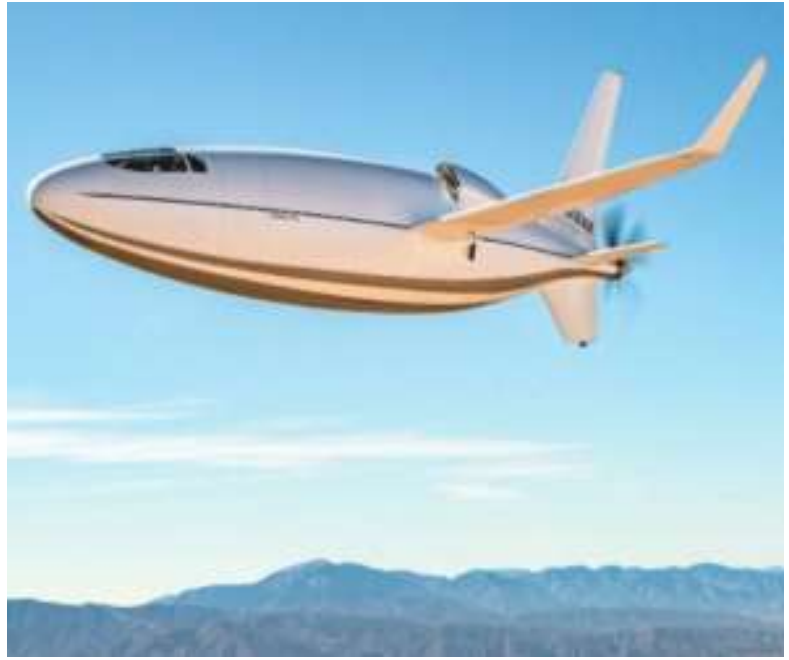

Fig. 22: The laminar-flow design of the Celera $500 \mathrm{~L}$ gives it a 4,500-mile range while its operating costs are about a sixth of competitive business jets

"I strongly believe that the use of hydrogen - both in synthetic fuels and as a primary source of energy for commercial aircraft - has the potential to significantly reduce the impact of the aviation climate," he added. There is still a lot to be done for this to become a reality. For example, airports should invest significantly in a facility needed to transport and supply hydrogen - if the idea is to mature beyond the conceptual stage.

Sooner or later, hydrogen will become the number one fuel for aviation and aerospace, whether it is burned or used as a raw material to obtain nuclear fusion energy directly on the spacecraft. Hydrogen is practically the future source of energy and the key to successfully solving the energy problem in aerospace and aviation but also in other industrial and civil fields.

This Wild New Aircraft Could Make Private Aviation as Affordable as Flying Commercial (Fig. 22).

The laminar-flow design of the Celera $500 \mathrm{~L}$ gives it a 4,500-mile range while its operating costs are about a sixth of competitive business jets.

The new Celera 500 L, which recently completed more than 30 test flights, plans to go wing to wing with business aircraft of the same size. But this clean-sheet design, which can pair most cities in the continental US, will have $80 \%$ fewer emissions than most business planes of the same size, about a sixth of the operating costs, according to its designer. Californian operator Otto Aviation intends to rewrite private aviation, making it as accessible as commercial air travel. "Individuals and families will be able to rent the Celera $500 \mathrm{~L}$ at prices comparable to commercial rates, but with the added convenience of private aviation," said William S. Otto, Sr., president and chief scientist of the company, in announcing the aircraft. The initial statistics 
are impressive. Celera's top cruising speed exceeds 460 $\mathrm{mph}$ - similar to most light aircraft - while its fuel economy of 18-25 miles per gallon makes it fuelefficient compared to similarly-sized jet aircraft, which reach only $2 \mathrm{mph}$. $3 \mathrm{mpg}$. Operating costs of \$ 328 per hour are also significantly lower than the $\$ 2,100$ per hour for the conventional business jet. At 4,500 nautical miles, the Celera also has the transcontinental range of a large aircraft.

Flat wings are traditionally strong, thick and robust, but a NASA-led team of researchers has created a flexible wing that transforms as it flies. With a width of $14 \mathrm{~m}$ or four meters, the new wing is built of thousands of units that fit together and work similarly to a bird's wing, says one of the report's authors, NASA research engineer Nick Cramer. "Something like a condor will lock its joints during the cruise, then (adjust) its wing in a more optimal shape for the cruise and when it wants to make a more aggressive maneuver, it will unlock its shoulder. Here, "he said in a telephone interview (Fig. 23).

But it's not just how the new wing works that differentiate it, according to researchers who co-authored a paper published this week in the journal Smart Materials and Structures.

The main areas of the airline's innovative activities:

- Development and production of a new transport product

- Improving the commercial characteristics of transport on developed routes

- Mastering new and improving existing work technology in all functional areas of activity

- Development of innovative potential

Most aviation enthusiasts associate supersonic flights with Concorde, but its last commercial flight took place in October 2003. There was also a Tupolev Tu-144, but it was in circulation until June 1978. Subsequently, supersonic aircraft was abolished due to the massive noise, the exaggerated degree of polluting emissions, the incredible consumption and, last but not least, the price of a trip.

Now, they are trying to bring the supersonics back to the present, by partially remedying the problems that led to their elimination. This category also includes Boom Supersonic, which has been in research and development for about 6 years. Before unveiling a generously sized creation for passengers, Boom just announced the XB-1 (Fig. 24).

Boom XB-1 was created as a concept aircraft, for testing technologies that will be integrated into a significantly larger edition for passengers. Test flights with the little XB-1 will start in 2021 (Fig. 24).

If all goes well, Boom could create the first completely new supersonic plane of people in about half a century. The first public details about this project began circulating on the Internet in August this year.

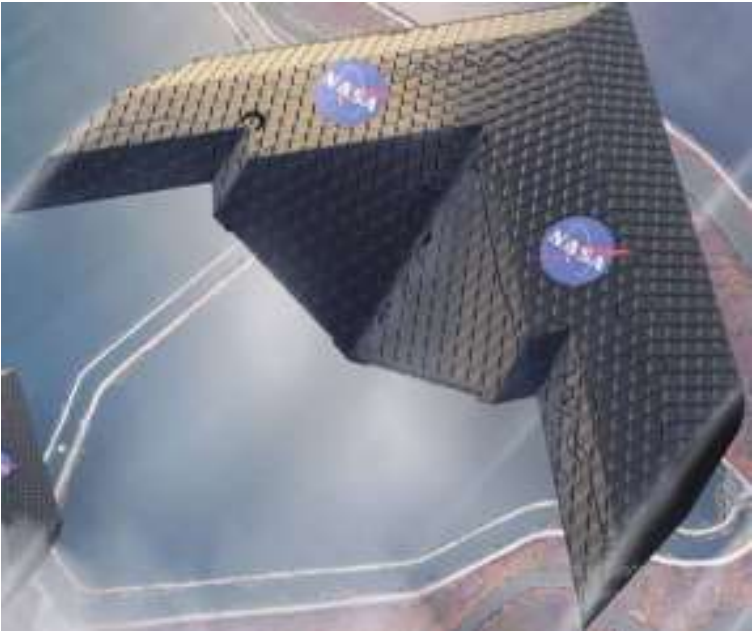

Fig. 23: The new plane wing moves like a bird's and could radically change aircraft design

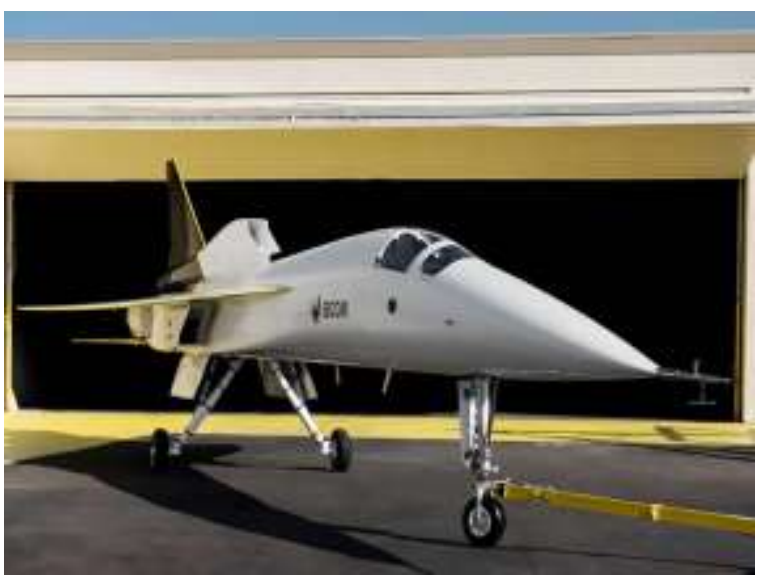

Fig. 24: Test flights with the little XB-1 will start in 2021

Boom XB-1 or Baby Boom has a length of $21.6 \mathrm{~m}$ and is built around a composite carbon fiber frame. Propulsion is provided by 3 General Electric J85-15 engines, designed to provide 12,000 pounds of thrust. It is important to note that the J85 is a long-range engine on the market since the $1950 \mathrm{~s}$, but it seems to have been optimized to minimize the polluting impact on the environment.

To materialize this concept, Boom collaborated with Stratasys and Velo 3D to reduce production costs by 3D printing of several parts. In the future, the company's creators hope to create the first supersonic Overture for passengers in 2025, with the first commercial flight taking place in 2029.

Electric aircraft manufacturer Pipistrel is advancing plans for a pair of new cargo aircraft and a 19-seat regional aircraft. In the May 13 newsletter from its US distributor, the Slovenian company indicated that it intends to focus on these new developments more urgently than on its plans for the Pipistrel 801 eVTOL, 
which was selected by the Uber rideshare group for the planned Uber air, urban product of air mobility (Fig. 25). "The changes to the company's priorities came after delays with the Uber flight taxi program by many international aviation authorities," the company said: "The continued extension of the deadline for the development of a flying taxi service, which was commissioned by the American company Uber, has given Pipistrel time to investigate future opportunities, some of which have been in the planning and development for several years." Uber Air services are to be launched in 2023 in one or more early adopted cities that the company has identified, including Dallas, Los Angeles and Melbourne, Australia. "We continue to see progress against our vision for Uber Air among many of our vehicle partners, despite the challenges that come with Covid-19," Uber Air told AIN. "We expect some partners to proceed faster than others, but we remain focused on preparing for Uber Air's commercial service on our own terms." Pipistrel is one of the eight "vehicle partners" selected by Uber, the others being the subsidiary of Boeing Aurora Flight Sciences, Bell, Embraer X, Hyundai, Jaunt Air Mobility, Joby Aviation and Karem Aircraft. The company insisted that it remains fully engaged as Uber's Elevate project, which is preparing for the launch of Uber Air. A Pipistrel spokesman told AIN that it had decided to "reduce the intensity" of the development on the grounds that "due to regulatory and other constraints" it would not be realistic to access the 801 eVTOL service by 2028 .

"The 801 project was never interrupted, but continues at a slow pace, in favor of accelerating the delivery of large cargo UAVs," the company explained. "We keep both projects in parallel, allowing the use of the same development methodology and tools for both vehicles." The project flew several scale models and performed large-scale system tests in the meantime." One of the cargo planes now advanced by Pipistrel has a design similar to the 801 eVTOL and would carry a payload of 660 pounds, about 200 miles. The company said it plans to deliver the first aircraft to an undisclosed Asian customer in 2022, but has not yet released further details about its performance and specifications. The second cargo plane is a fixed-wing design based on Alpha Pipistrel light electric aircraft. It is developed to be piloted or remotely piloted and would be used for missions such as humanitarian aid, the packages being thrown from the pods on each side of the wing and a payload of almost 250 pounds.

Meanwhile, Pipistrel is working on the development of a 19-passenger aircraft that it says would fly routes of up to 300 miles at about a quarter of the operating cost of conventional aircraft. The company reported that the so-called Miniliner concept could be ready for launch in 2028. The company explained that the 19-seater aircraft is part of the Unifier 19 project, being developed in partnership with various undisclosed academic partners.
The paper leverages the efforts of a separate Mahepa project, led by Pipistrel, which develops and tests various new propulsion technologies, including electric fuel cell and hydrogen propulsion systems. The Pipistrel team hopes to start testing the flight of a prototype for this design before the end of 2020 .

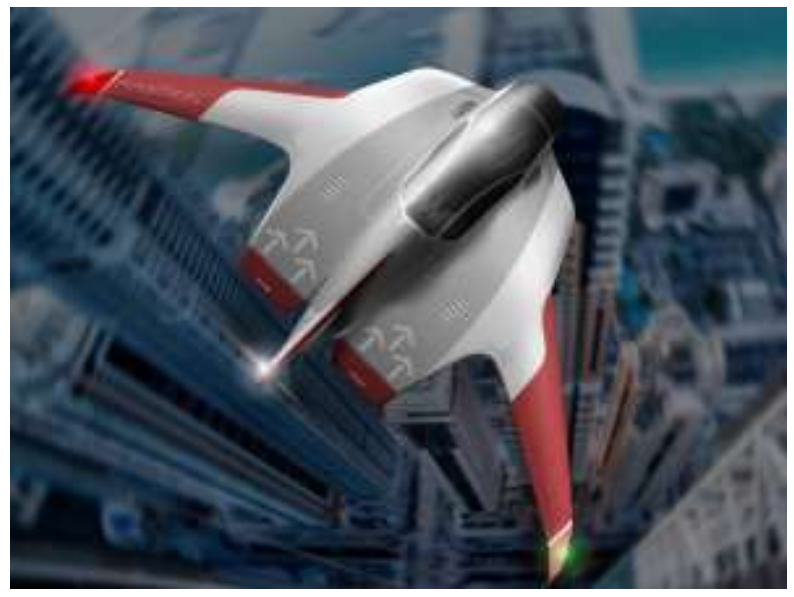

Fig. 25: The Pipistrel 801 eVTOL

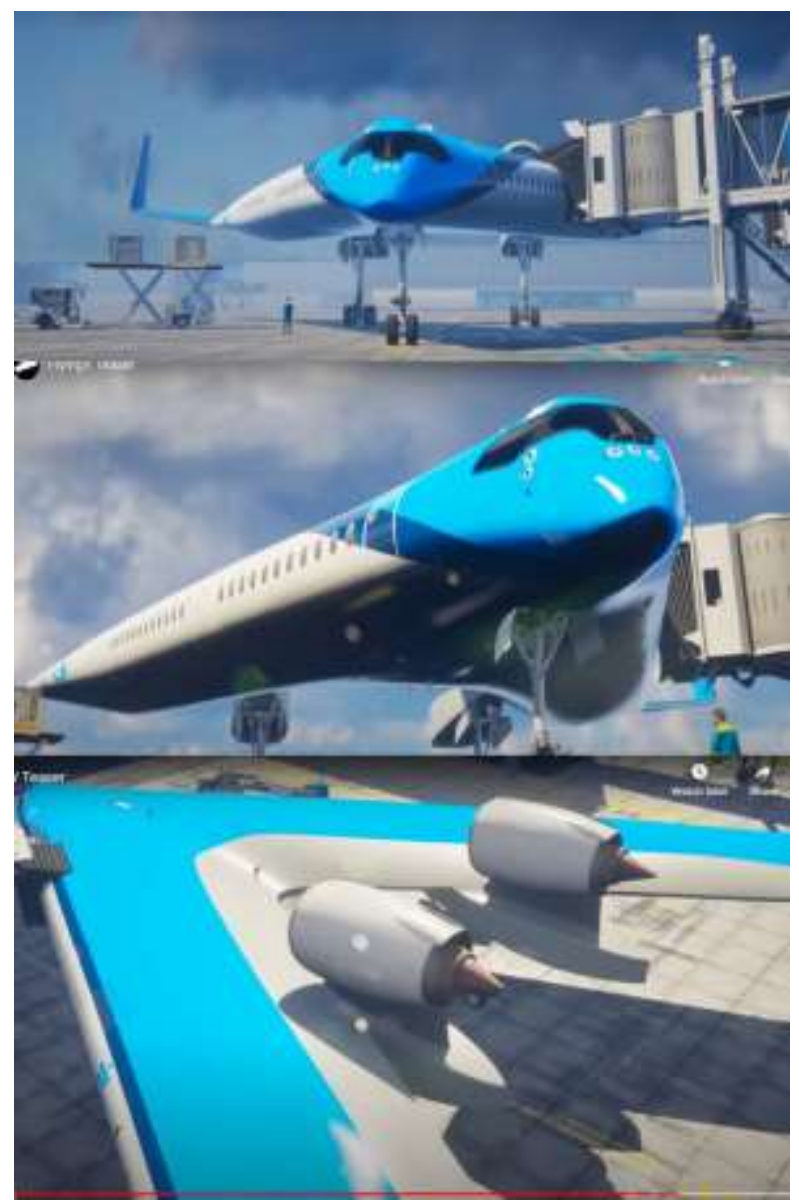

Fig. 26: The Flying-V concept 
Aerospace engineers at the Delft University of Technology in the Netherlands have come up with a new, highly innovative concept that aims to integrate the passenger compartment, cargo hold and fuel tank into a V-wing model (Fig. 26).

The result is a super sleek aircraft with an advanced futuristic look that manages to use $20 \%$ less fuel than the Airbus 350.

This new concept started as a dream imagined by Justus Benad, a student at the Delft University of Technology, in his thesis project at Airbus Hamburg, a concept that enhances the traditional bird-like design very long fuselage with wings on both sides - and makes wings the main storage space of the Aircraft.

Such a design also offers a unique opportunity to rethink the passenger experience, a pleasant and unforgettable experience, said Peter Vink, professor of applied ergonomics and design.

"This new form of aircraft creates interesting opportunities for us to rediscover the interior of a modern passenger aircraft, leading to a much more comfortable flight for them. As an example, an integral part of Flying-V research, we are looking for new options for passengers. to be able to rest or eat in an airplane. An airplane should no longer be a way of stress but on the contrary."

The aircraft is powered by turbofan engines located above node V. At $65 \mathrm{~m}$, the wing opening has been designed to be the same as the A350, allowing it to be used on existing infrastructure such as airports, gates, runways and hangars without difficulty. Like a smaller version of the A350, the Flying-V has a smaller inlet area, resulting in lower forward resistance, leading to a dramatic drop in concept aircraft fuel consumption. It will also require much less fuel for long-distance travel, given that today global aviation is responsible for $2.5 \%$ of total carbon emissions, a figure that will increase as air travel continues to increase and they.

Last autumn, the Dutch aviation sector proposed a plan to reduce $\mathrm{CO}_{2}$ emissions by $35 \%$ by the end of 2030. A flying prototype will be unveiled at Amsterdam Schiphol Airport in October, as part of KLM's 100th anniversary.

In the video from which I extracted Fig. 26-30, in addition to the $\mathrm{V}$-plane, other new future concepts are presented that want to change the way they fly radically, so that passengers feel comfortable, like at home, sitting in comfortable and pleasant armchairs and practicing what they would have done at home (to work on a laptop, to watch a movie on it, to relax in any other way, while they will fly over very long distances fast and safe but especially comfortable).

The V-shaped model has already been shown in Fig. 26, in Fig. 27 being briefly presented another Airbus prototype having a $\mathrm{V}$ with a slightly smaller aperture than the previously presented model and the wings compactly connected together and with the central body of the new aircraft concept.

The aerodynamics of the concept Maveric in the Fig. 27 is fantastic. The interior of the aircraft is designed to offer special comfort to the passengers, having the possibility to impose on them some sensations of peace and calm, of real relaxation.

Lilium will be a new fully electric air taxi that will have increased autonomy and a relatively high speed compared to other similar models (Fig. 28).

Daniel Wiegand, the Lilium designer, hopes that his new concept will become a very cheap future air taxi, allowing him to fly between two big cities for only $\$ 70$.

It has been wanted for a long time to build civil air taxis, but this year more than ever new and new models have appeared in this sense so that in the future they can be tested and later successfully introduced into circulation and the models will not it was too late to multiply and diversify further. They must be cheap in addition to the main features of flight safety and comfort.

Daniel's model already has this great advantage of its use at low costs for the manufacturer, user and passengers.

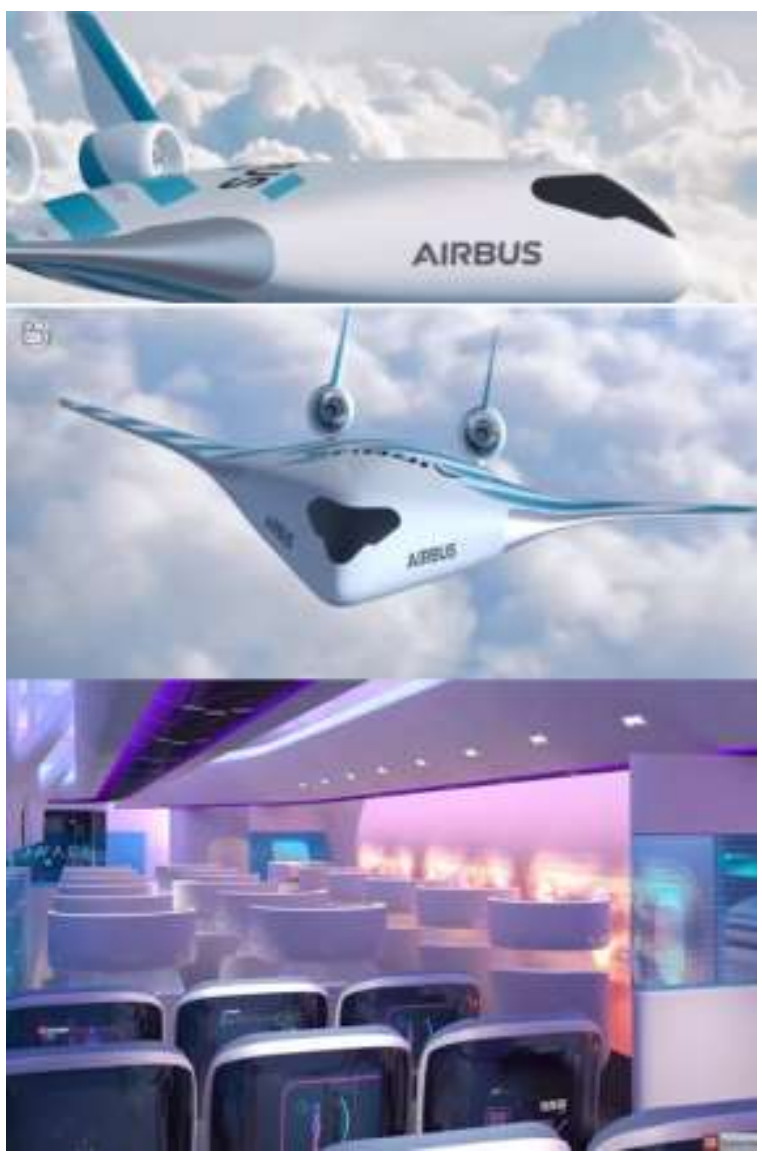

Fig. 27: The new Airbus Flying compact concept Maveric 


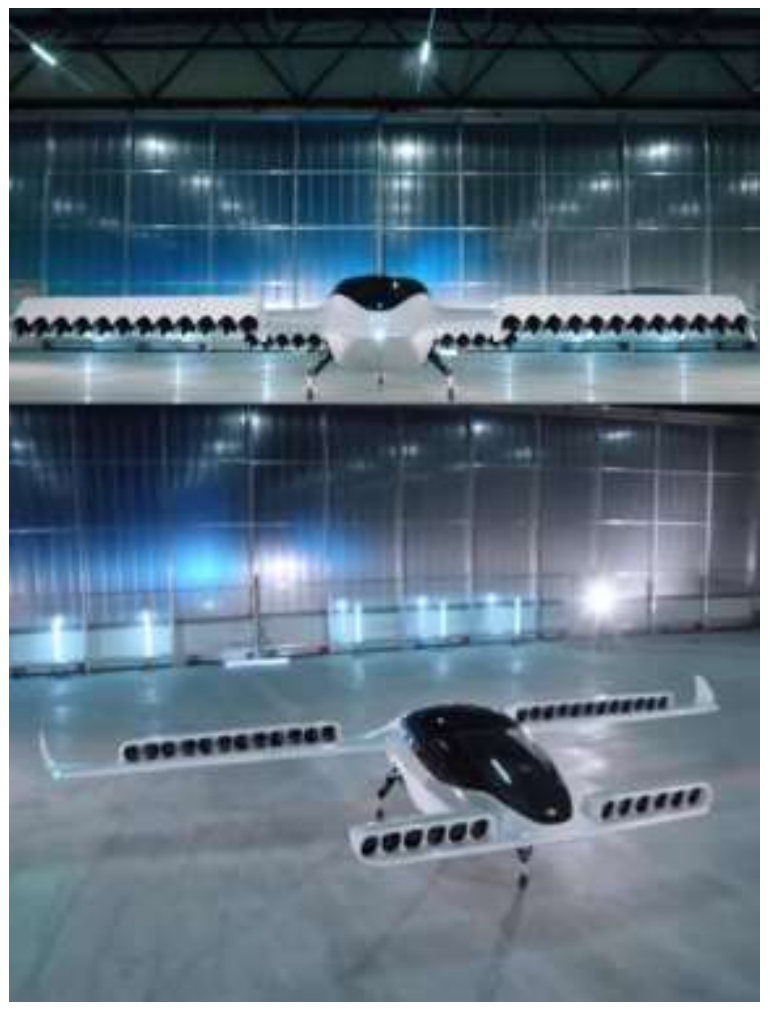

Fig. 28: The Lilium electric air taxi

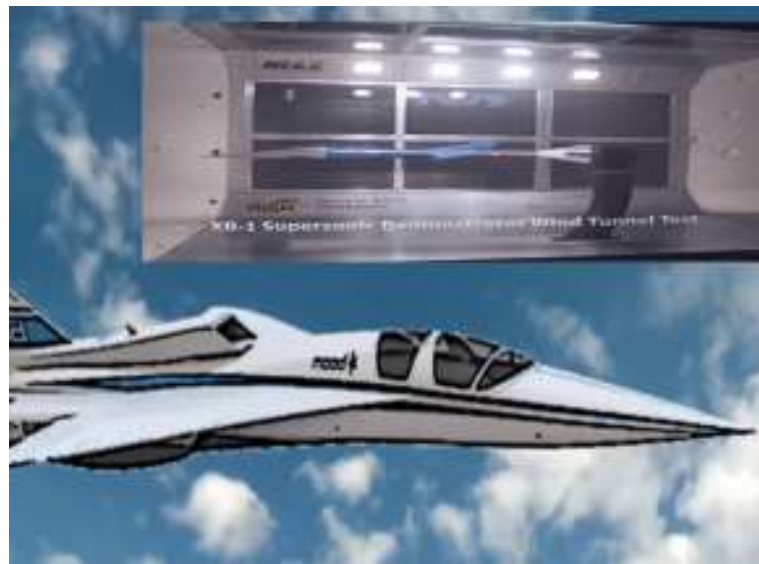

Fig. 29: The supersonic Baby Boom

Virgin Galactic is working with Richard Branson on Baby Boom, a new supersonic project that will fly from New York to London in just three hours, being a worthy successor to the Concorde due to its average supersonic speed of $2335 \mathrm{~km} / \mathrm{h}$ (Fig. 29).

Progress Eagle (Fig. 30) will have 0 (zero) emissions and will carry over 800 passengers at very high speeds and in super pleasant comfort.

The US says it has tested a top-secret sixth-gen fighter. The aircraft was created using digital engineering, which allows the service to bypass the regular manufacturing process (Fig. 31).

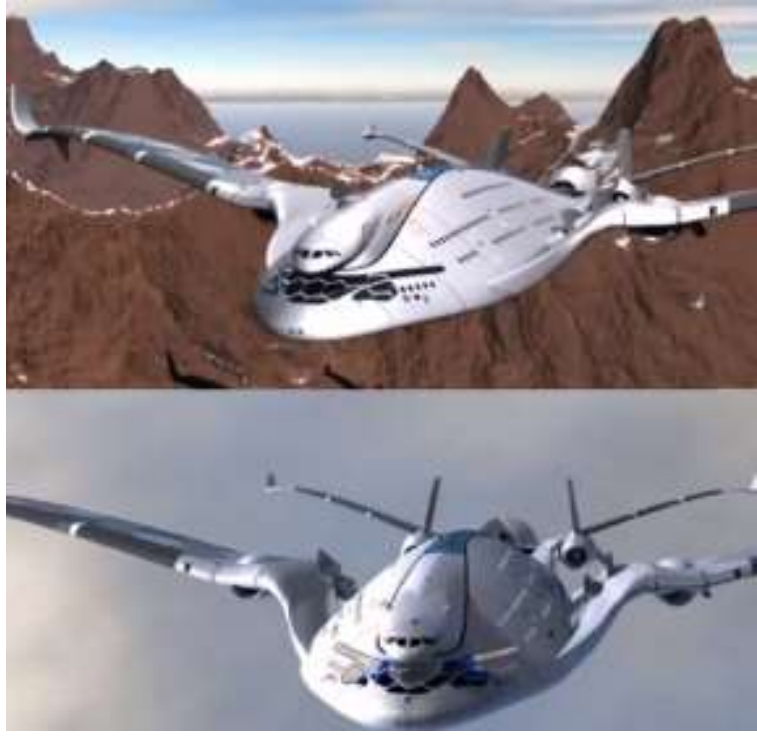

Fig. 30: The progress Eagle

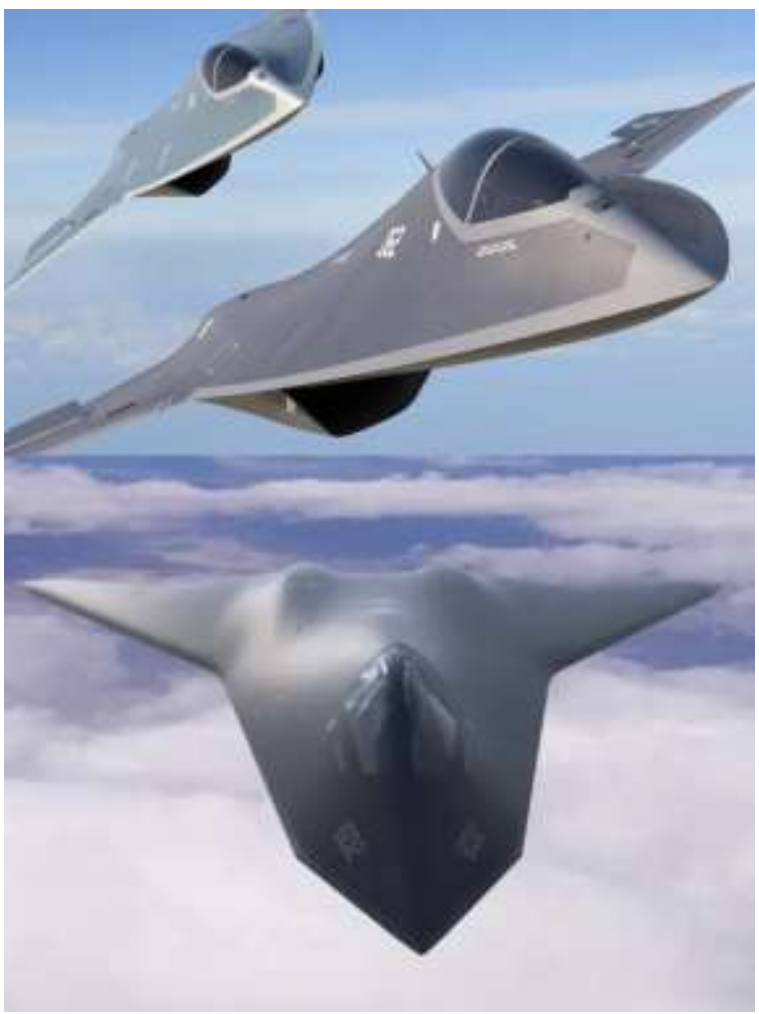

Fig. 31: The US top-secret sixth-gen fighter. It has Laser shooting weapons

The US top-secret sixth-gen fighter has Laser shooting weapons.

Samad Aerospace tells us that it has managed to develop a new two-seater VTOL concept, the Q-Starling, which was inspired by various places and modes from the Mustang P51 to the Hawk fighter to the Maserati, but 
there is something nautical in width and in its shape reminiscent of the beak of ducks while its rear is narrowed aerodynamically as in turbo or supersonic aircraft. Its unique appearance inspires a sense of innovation that extends even to the function and mission of Q-Starling. The company declares it to be a "jet aircraft", one of the few VTOLs in the Personal Aviation Vehicle (PAV) category, the Q-Starling being not a helicopter or drone design, but rather two-seater wings, or perhaps better said a combination. The company believes that the design will be an advantage in the early stages of VTOL adoption, as the design of the aircraft is more in line with existing regulations on air traffic and landing infrastructure. Eventually, it will function as a VTOL aircraft. For take-off and landing, the large doors at the bottom open to expose a large moving fan powered by a hybrid diesel-electric turbo-generator and a battery bank. Stability and maneuverability are ensured by the lower wing tips and rear fans. Once the doors are closed, the large fan creates enough forward traction to generate a projected cruising speed of $300 \mathrm{mph}$ with a range of 500 miles (Fig. 32).

It cannot be said that there are shortcuts to aviation safety - it is up to engineers to manage budgets and safety risk programs, even when testing new types of aircraft, such as eVTOL.

Air consultancy Roland Berger counted 170 electric planes developing worldwide for a study published in July last year, but it is estimated that the number will increase to almost 200.

By far, the largest number of these aircraft are electric Vertical Take-Off and Landing aircraft (eVTOL) - clean sheet metal projects using electric propulsion trains and propulsion systems in completely new ways. Development programs are taking place mainly in the US and Europe, where many start-ups are beginning to face the reality of transforming CAD drawings into metal and composite materials moving in the sky.

Bristol-based Vertical Aerospace, based in the UK, hopes to be one of the first companies on the market with an eVTOL aircraft. The company intends to complete the testing and certification of its first aircraft by 2023 and start services on short-haul flights. During operation, Vertical intends to extend the range of the aircraft and, finally, to introduce its range, while extending the number of routes it can serve. The company, which was founded in 2016, flew the first demonstration of the concept at Cotswold Airport in the UK in June 2018. Vertical engineers recently completed the flight test of the second large prototype, called Seraph, which weighs $1000 \mathrm{~kg}$, it can reach speeds of up to $80 \mathrm{~km} / \mathrm{h}$ and carry loads of up to $250 \mathrm{~kg}$. Seraph, which underwent ground tests a few months ago, takes design clues from multi-rotor drones and, like many eVTOL aircraft, can be described as an enlarged drone. Seraph has completed its first flight testing campaign without major incidents, thanks in large part to Paul Harper, the chief certification engineer at Vertical Aerospace. Harper is responsible for ensuring the safety of Seraph flight tests and liaising with the UK Civil Aviation Authority (CAA). He said: "We started as a small group of people in charge of taking over the drone technology and expanding it into a useful aircraft.

A new presentation of a new development concept of the old B 21 Raider launched by the US Air Force (USAF) of the top-secret Northrop Grumman B-21 Raider presents seemingly subtle but obvious differences compared to its predecessor stealth bomber, Northrop Grumman B-2A Spirit.

It describes the bomber parked in hangars at several US air bases, which is expected to host the flying wing in the future, including Dyes Air Force Base (AFB) near Abilene, Texas; Ellsworth AFB, near Rapid City, South Dakota; and, Whiteman AFB near Kansas City, Missouri (Fig. 34).

Rolls-Royce earlier created an M250 hybrid power system and performed ground tests. The APUS i-5 aircraft will now be used to demonstrate its integration with an aircraft.

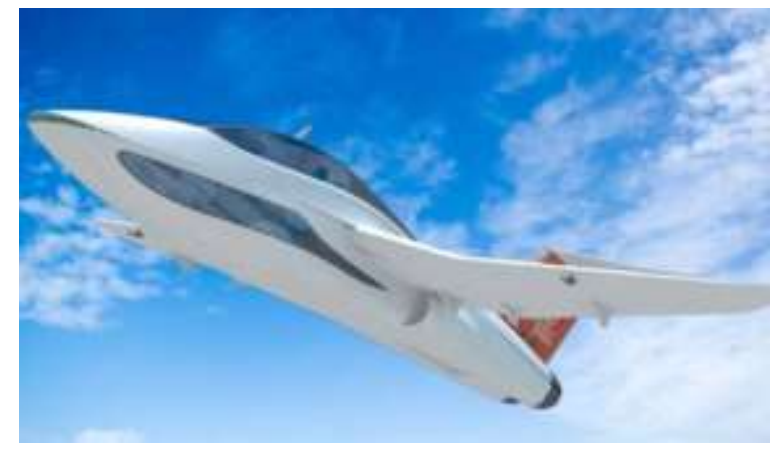

Fig. 32: The Samad Aerospace tells us that it has managed to develop a new two-seater VTOL concept, the Q-Starling

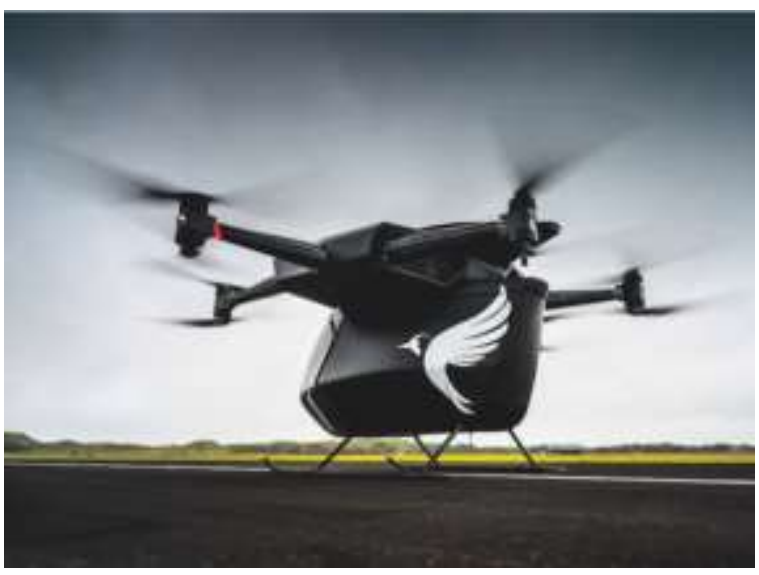

Fig. 33: The Vertical Aerospace's latest prototype, Seraph, can fly at speeds of up to $80 \mathrm{~km} / \mathrm{h}$ and carry $250 \mathrm{~kg}$, the equivalent of three passengers 


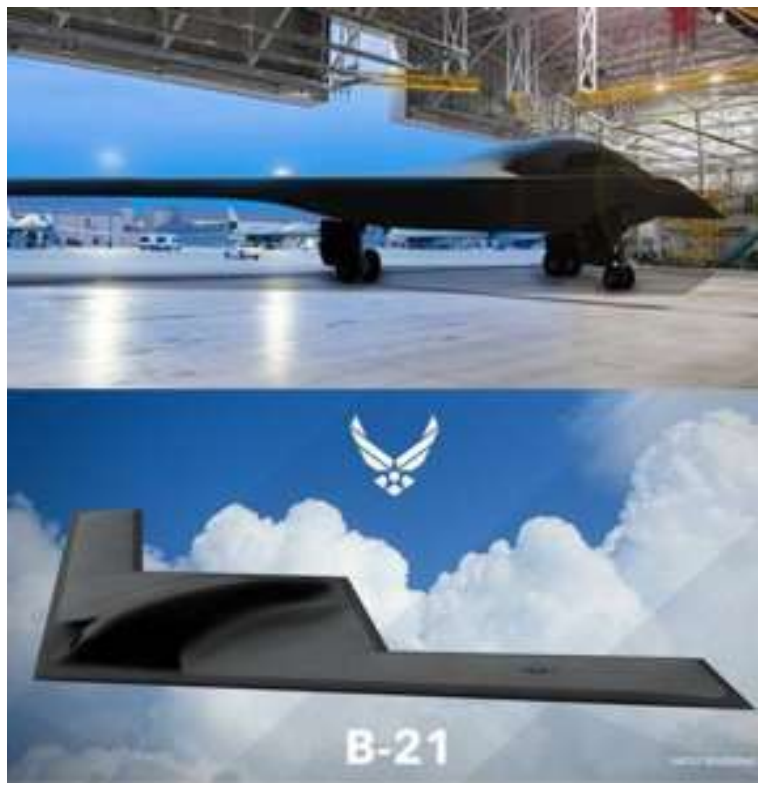

Fig. 34: A new presentation of a new development concept of the old B 21 Raider launched by the US Air Force (USAF)

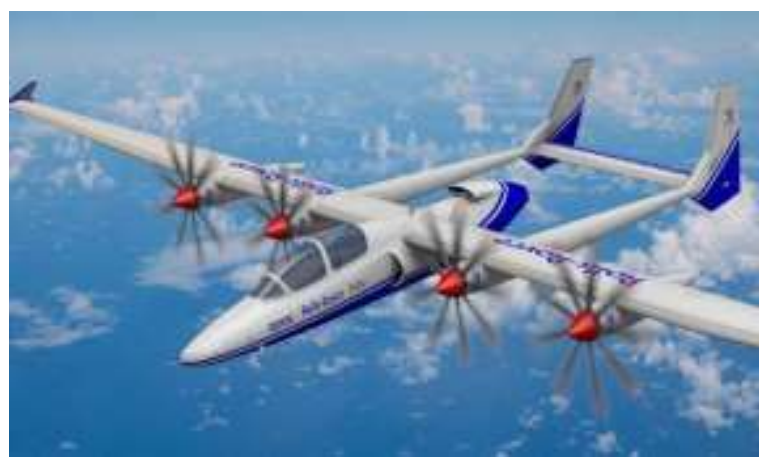

Fig. 35: APUS i-5 Rolling-Royce hybrid electric demonstration aircraft

The M250 hybrid package also complements systems developed for larger aircraft, as seen with the E-Fan $\mathrm{X}$ demonstrator

Earlier this year, Rolls-Royce announced that it was conducting ground tests of a hybrid-electric propulsion system built around a turbo engine with an M250 shaft. All he needed now was to find an airframe in which to integrate the system. Rolls-Royce has now discovered that aircraft and taken another significant step toward achieving its ambition to provide hybrid-electric propulsion systems for the next generation of aviation (Fig. 35).

A futuristic Flying Vehicle like in Star Wars is projected in secret for the US army (Fig. 36).

The flying bicycle can transport 2 people at $70 \mathrm{~km} / \mathrm{h}$, being a very small but powerful vehicle with enough autonomy to transport a passenger from one place to another, for rescue missions and quick evacuation (Fig. 37).

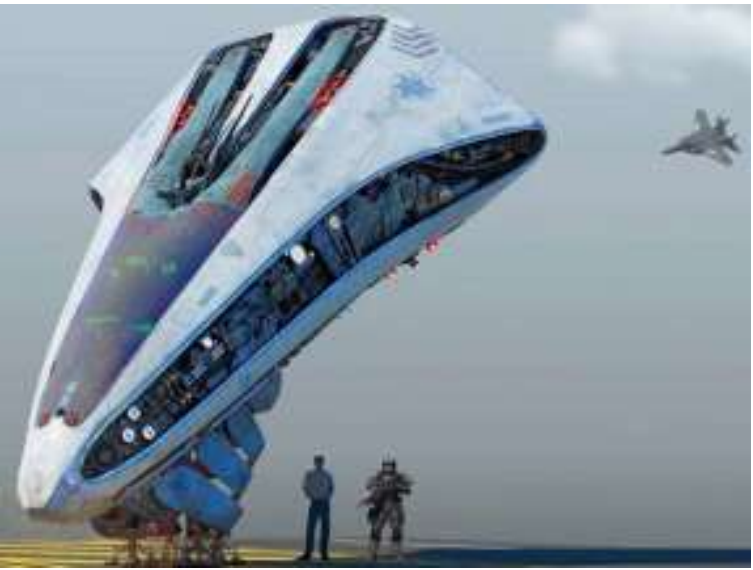

Fig. 36: A futuristic Flying Vehicle like in Star Wars is projected in secret for the US army (Fig. 36)

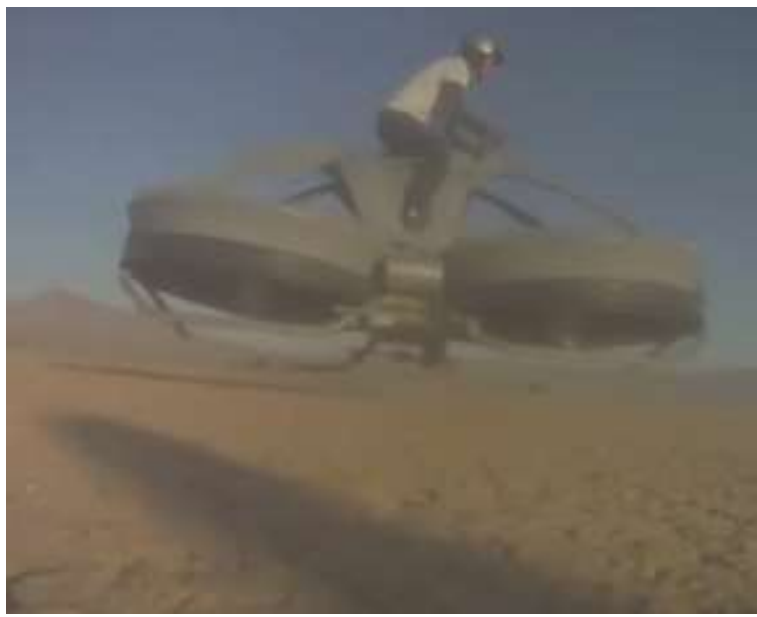

Fig. 37: The flying bike

The flying mansion (Fig. 38) is designed in such a way as to become a flying house, or rather a flying palace, being equipped with lounges, bathrooms, kitchen, living room and luxurious bedrooms, swimming pool and practically everything comfort desired by anyone, being one of the largest flying vehicles currently available, with great comfort, extraordinary safety, easy maintenance in the air, low fuel consumption, it can be designed with zero emissions, only with electric motors.

Obviously maintaining at a certain altitude without fuel consumption, in great safety, is done with the balloon, the aircraft being in fact a modern airship, which has the additional possibility to move at high speeds, to stay in the air at any altitude safely without energy efforts.

A similar model is shown in Fig. 39, which also has facilities for leisure in the air, long and very long journeys, pleasant, comfortable and safe, which will compete with those on water, sea and oceans so far. Probably many retirees with financial possibilities will embark in the future on such an aircraft, replacing the classic pleasure tourist routes on transatlantic ships. 


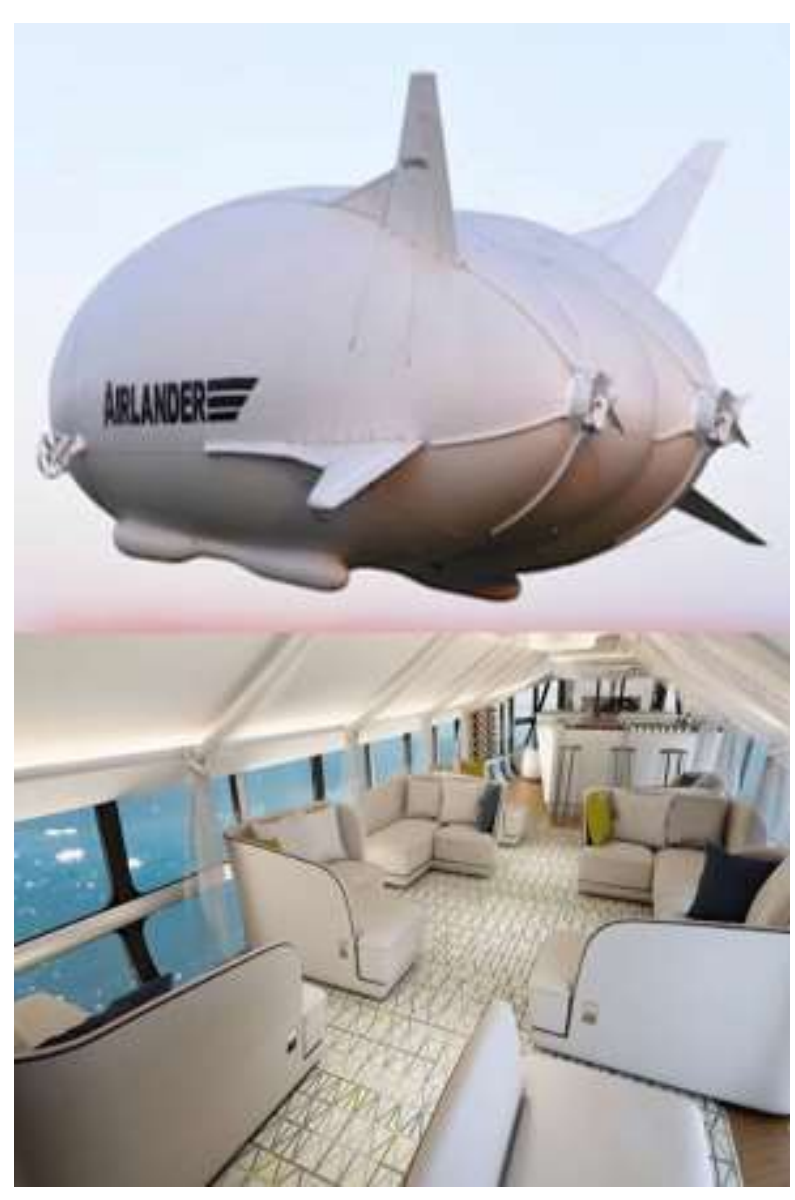

Fig. 38: The flying Mansion

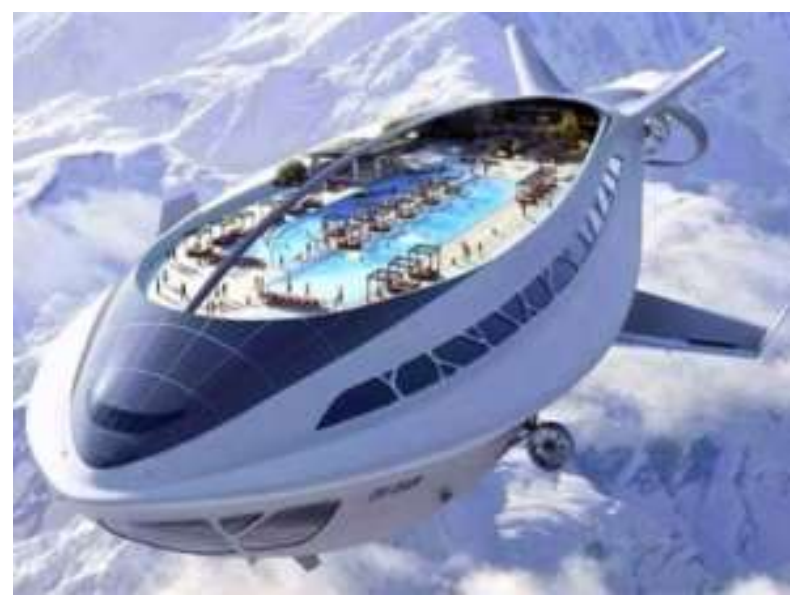

Fig. 39: The most expensive Private Jets in the world

\section{Hexplane, or the Hybrid with Six Helicopter-Type Passenger Engines}

V-22 Osprey is a very bold futuristic concept imagined and thanks to today's drones with $3,4,5,6$, or $n$ helicopter engines (Fig. 40).

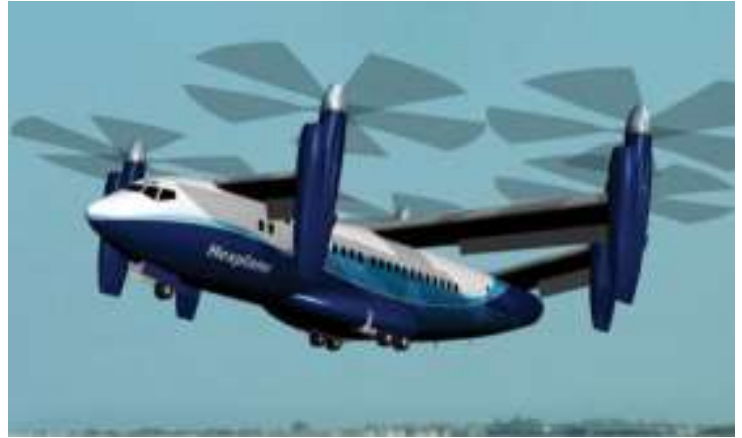

Fig. 40: Hexplane, a Six-Engine Airliner-Helicopter Hybrid

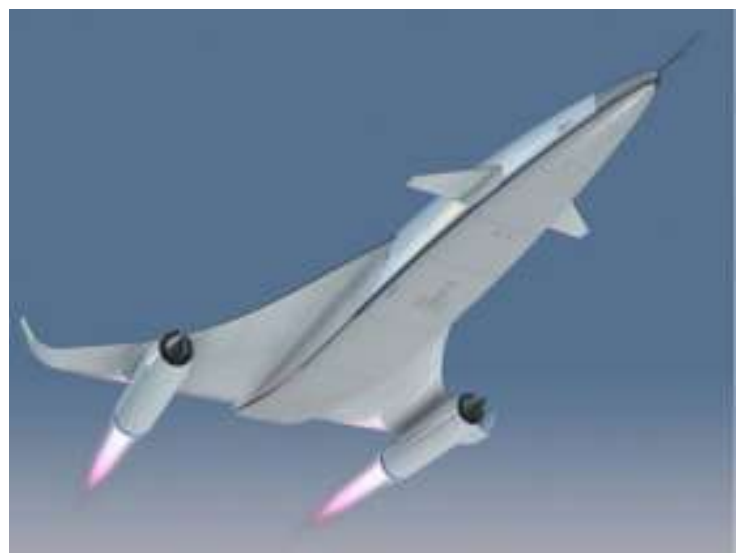

Fig. 41: Reaction Engines testing ammonia as carbon-free aviation fuel

Reaction Engines testing ammonia as carbon-free aviation fuel (Fig. 41).

Reaction Engines and the UK Council for Science and Technology Facilities (STFC) have jointly launched an important study aimed at fuel diversification and have succeeded in finalizing a concept of how practical it is to introduce and use ammonia as a fuel for jet aviation Reaction Engines heat exchanger technologies and STFC's advanced catalysts were used to create a new, reliable, lowemission propulsion system for the immediate future.

Today's modern jet engines already use a wide variety of kerosene-based fuels, all of which have a very high energy density, so that they can propel aircraft far beyond the speed of sound and transport passengers and goods around the globe extremely quickly and safely. The downside of these current types of fuels is that they also come from fossil fuels and produce significant carbon dioxide emissions, which the airline industry and many governments have made a serious commitment to drastically reduce them until 2050.

One possibility to achieve these reductions is precisely the analysis and then the introduction of conventional jet fuels to supply aircraft with a low percentage of pollution during operation. But the major problem with all the 
alternatives already studied so far is that most of these alternatives have much lower energy densities than standard aviation fuels. On the other hand, for example, current battery technology would require that future aircraft be very small, with a short-range and an extremely low charging capacity. For this reason, today when we talk about electric motors in aviation we either think of hybrid solutions that burn classic fuels and generate electricity that then power the electric motors or small planes with electric batteries that do not allow fast and long-distance flights or very large and the weight they can carry is also very low. In the meantime, liquid hydrogen could be a viable alternative and today from today's perspective only hydrogen is the most powerful nonpolluting fuel that can be massively deployed in aviation, with already permitted methods in place, but has not yet been mass introduced. it still requires many studies, major technological changes, other infrastructure, new devices for production, storage and use, but it should be transported so much that the aircraft should be completely redesigned and a new aerospace infrastructure built.

The idea of using ammonia as aviation fuel is not entirely new. Although it has only a third of the energy density of diesel, ammonia is easier to liquefy and store and in addition it has already been tested and used by the famous X-15 rocket aircraft, propelling it into space at a whole series of suborbital missions from the $1950 \mathrm{~s}$ and 1960 s. In addition, it does not contain carbon and will not pollute the environment with all kinds of byproducts of carbon and oxygen resulting from the burning of hydrocarbon fuels.

Its most difficult point is the achievement of an economically and financially viable way for its massive introduction into aviation. To this end, Reaction Engines produced a new propulsion system based on the heat exchanger technology it developed for its SABER hypersonic engine, which was then evaluated by STFC's Rutherford Appleton Laboratory near Didcot in Oxfordshire. In this new system, ammonia is practically stored as a pressure-cooled liquid in the wings of the aircraft, similar to kerosene-based fuel. The heat obtained from the engine by the heat exchanger will heat the ammonia as it is pumped and fed into a chemical reactor where a catalyst breaks down some of the ammonia into hydrogen. The fuel actually used will therefore not only be ammonium but a higher ammonia/hydrogen mixture then sent to the jet engine, where it burns like a conventional fuel, although the emissions consist mainly of nitrogen and water vapor. So the only major pollutants could be some combinations of nitrogen, much less harmful than those of carbon and oxygen. The solution at the end, therefore, uses not only ammonium but ammonium and hydrogen obtained on the ship itself (in this way it is no longer necessary to produce and store hydrogen in special devices).
According to reaction engines, the energy density of ammonia is not enough to create additional problems for engines and aircraft in the sense of the need for constructive and technological changes, but perhaps only some insignificant changes so that the engine can be upgraded in a relatively short time. A ground test is currently underway, with a first possible flight in a few years.

"The combination of Reaction Engines' transformer heat exchanger technology and STFC's innovative catalysts will start a new class of fuels based on air propulsion systems that will use green ammonia," says Dr. James Barth, chief engineer at reaction engines. "This study showed that an ammonia-powered jet engine could be adapted from currently available engines, while ammonia as a fuel does not require a complete reconsideration of the design of civil aircraft as we know them today. In this way it will be possible to make a rapid transition to a future of sustainable aviation at a low cost; ammonia-powered aircraft could serve the world's short-haul routes probably long before 2050."

The plane of the future will be faster, quieter and more comfortable, lighter and safer because various components will be made entirely of woven carbon carpets embedded in plastic called "composites". These materials offer both lightness and exceptional strength. Smooth, rivet-free surfaces ensure superior aerodynamics (Fig. 42).

A model of the Tempest jet fighter has been unveiled by the defense secretary, Gavin Williamson, at the Farnborough airshow (Fig. 43). The Secretary of Defense has revealed plans for a new RAF fighter jet, Tempest, which will eventually replace the Eurofighter Typhoon. In the Farnborough air show, Gavin Williamson unveiled a conceptual version of the sixthgeneration fighter jets that the Ministry of Defense (MD) expects to take out of the new air combat strategy, meant to maintain Britain's status as such "A military power after Brexit". This is a strategy to maintain air control, both at home and abroad, to remain a global leader in the sector, "said Williamson. A world leader in the air combat industry for a century, with a range of envied by skills and technology and this strategy clearly shows that we are determined to make sure it stays that way."

The government has said it will spend $£ 2$ bn on aircraft development between now and 2025, using the money allocated in 2015 for future air combat technologies, but has given no estimate of the overall cost of the Tempest program. Private companies also contribute funds and are believed to have spent hundreds of millions on planes so far. Tempest will be able to fly unmanned, according to plans launched by MoD and will have onboard the new generation technology designed to face modern threats. This will include "swarming" technology that uses artificial intelligence and machine learning to reach their targets, as well as targeted Energy Weapons (DEWs) that used concentrated laser blasts, microwave ovens, or particle beam energy to cause damage. Tempest will be built by a consortium led by British 
defense company BAE Systems, with engine manufacturer Rolls-Royce, Italian aerospace company Leonardo and panEuropean missile manufacturer MBDA.

At the 2011 Paris Air Show, aerospace giant EADS unveiled a fully electric propulsion system for a commercial aircraft that could be ready to fly in just 20 years. The aircraft, called the Voltaire, is a zeroemission, high-density, battery-powered aircraft that rethinks the design of conventional commercial aircraft to allow the change of the heavy-jet engine for an environmentally friendly battery system. The aircraft is powered by high-efficiency superconducting electric motors that operate reverse spiral propellers located behind the aircraft. The significance of this aircraft is not focused on the engineers' decision to sink a battery inside, but on the EADS team's understanding that in order to make electric airplanes a reality we will have to rethink not only engines but also aircraft propulsion systems and design (Fig. 44).

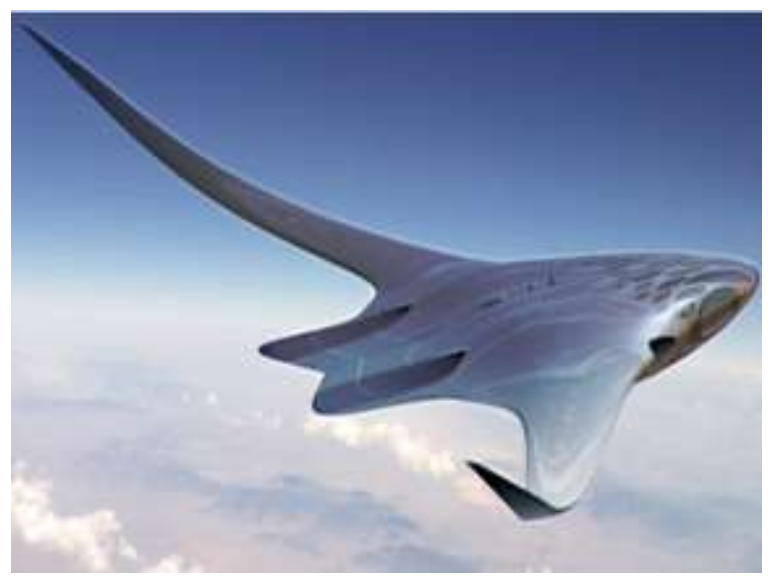

Fig. 42: A Voestalpine concept

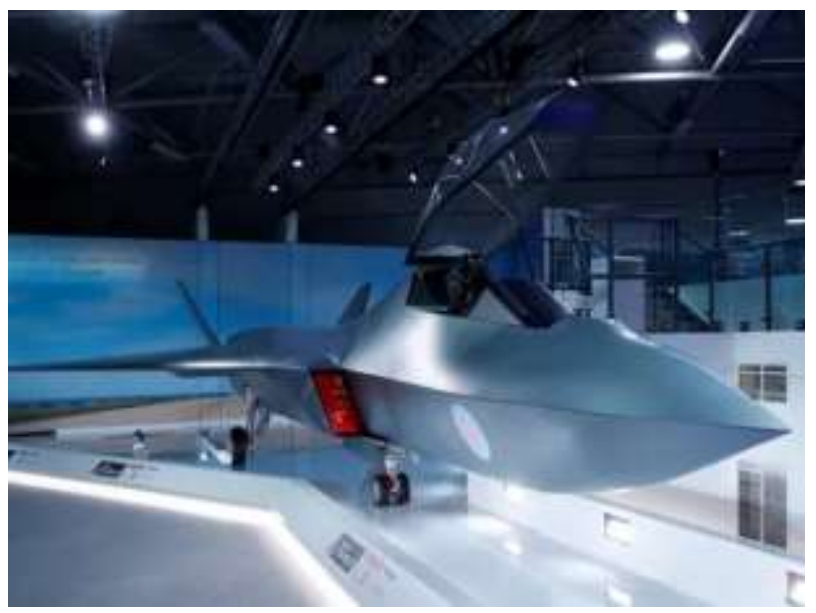

Fig. 43: A model of the Tempest jet fighter, unveiled by the defense secretary, Gavin Williamson, at the Farnborough airshow
EADS has thought of building the Voltaire project with two large batteries, each with a very high density, which is positioned in the hold so that they can be easily changed when the plane arrives at an airport. The discharged batteries will then be returned to a charging station in the same way that cargo and luggage are removed from an aircraft - a set of fully charged batteries to be replaced so that the aircraft does not waste time waiting to charge the batteries, so they are very easy to replace, wherever the plane will land. The rear propulsion system together with electric motors achieves great fuel economy, eliminates the huge noises of propulsion on classic fuels, fossil fuels, eliminates environmental pollution with already known classic pollutants that have completely destroyed nature's ecosystems thus achieving all dreams of humanity to fly smoothly without noise and noxious substances, without environmental pollution, without stress and in great safety, with a much high quality of flight. The proposed system aims to bring with it the success that the industry has had in the last 10 years and the batteries they need $1000 \mathrm{Wh} / \mathrm{kg}$ - in no more than 20 years, which would completely change the way they fly.

It is already hoped that flights to Australia and the US will soon be able to be made much faster in just a few hours, thanks to a new super powerful aircraft engine. Thus the British could arrive in New York in just an hour's flight with a plane powered by new technology (Fig. 45).

Flights could be very fast in the coming years, thanks to a very powerful new engine. The flight to New York could take just an hour and a trip to Australia could be completed in four hours with the new technology. The British company Reaction Engines is creating the super-engine that could see tourists throwing themselves around the world at full speed. The technology company said it intends to offer a "truly versatile propulsion system". It will be "an airbreathing hybrid rocket engine that can power an aircraft from a permanent start at a speed of sound five times faster for hypersonic flight into the atmosphere."

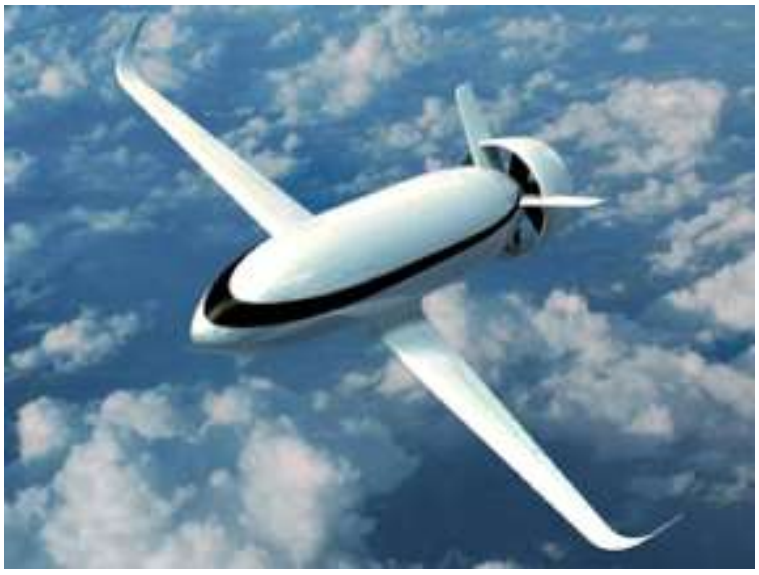

Fig. 44: EADS rethinks the way planes fly with new all-electric aircraft design 


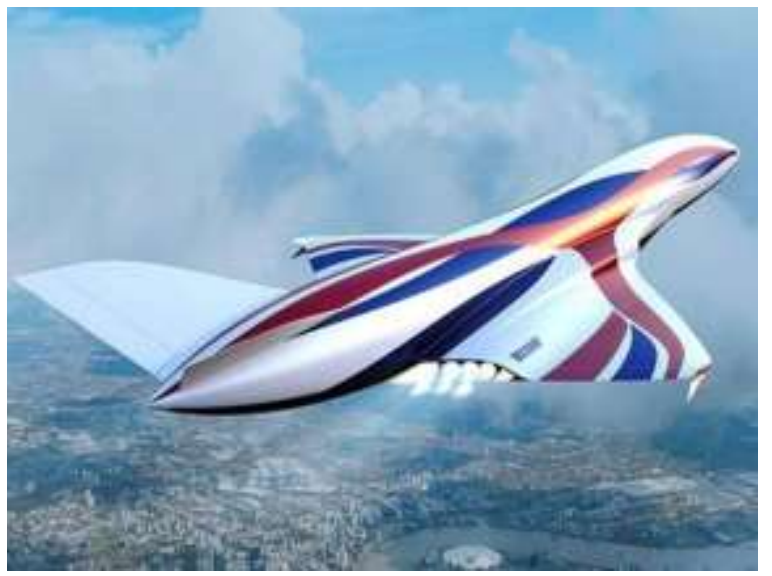

Fig. 45: British could arrive in New York in just an hour's flight with a plane powered by new technology

The engine is nicknamed the Engine of the Synergistic Breaking Air Missile (SABRE) and "represents a defining moment in motor flight". It will also power spaceships.

The British company Reaction Engines Ltd believes that its engine called the Sabre could be integrated into the fuselage of a spacecraft onboard which would function like an atmospheric jet engine and like the propellers of a rocket in space. Gear could take the place of rockets in terms of space travel and could revolutionize flight, minimizing air travel time.

In the preliminary tests that took place yesterday, the European Space Agency (ESA) said it was satisfied with the parameters and performance of the Sabre engine. The Skylon spacecraft exists only in the concept phase and what the British company has at the moment is a very efficient heat exchanger, capable of cooling the aspirated engine air at very high speeds, from 1,000 to $150^{\circ} \mathrm{C}$ Celsius degrees $\mathrm{C}$, in a hundredth of a second, all without freezing the components, which would damage the mechanisms.

This essential technological implementation solves one of the basic constraints that limit jet engines to a maximum speed of about 2.5 times the speed of sound, a value that Reaction Engines engineers believe their engine can double. The Sabre engine could therefore move an aircraft through the air with five times the speed of sound, at an altitude of $25 \mathrm{~km}$, about $20 \%$ of the speed and altitude needed to reach the orbit of the planet. To get into space, Sabre engines would switch to rocket mode to make up for the remaining 80 percent.

We also talked about the super-powerful Sabre engines when we presented the engines of the Skylon aircraft (Fig. 46), so it was normal to mention these super motors of their future, their more evolved descendants and the endowment with such advanced engines continuous to other ultrafast super aircraft.

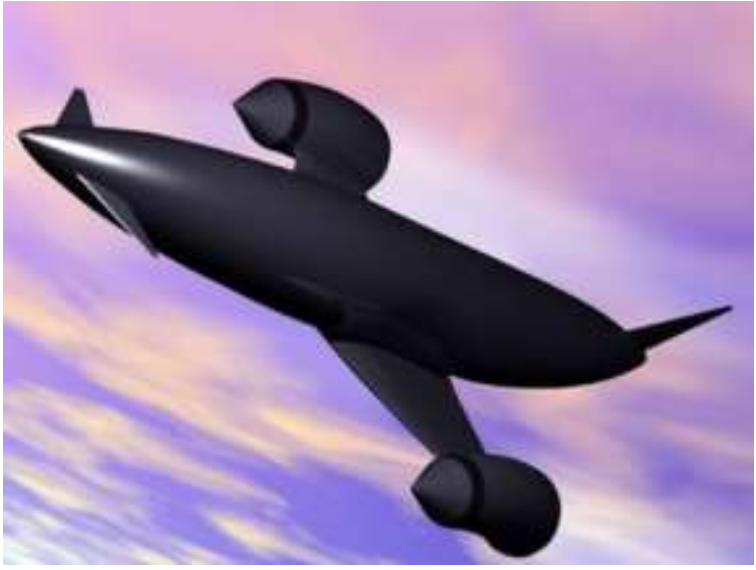

Fig. 46: Skylon aircraft with the super motor Sabre

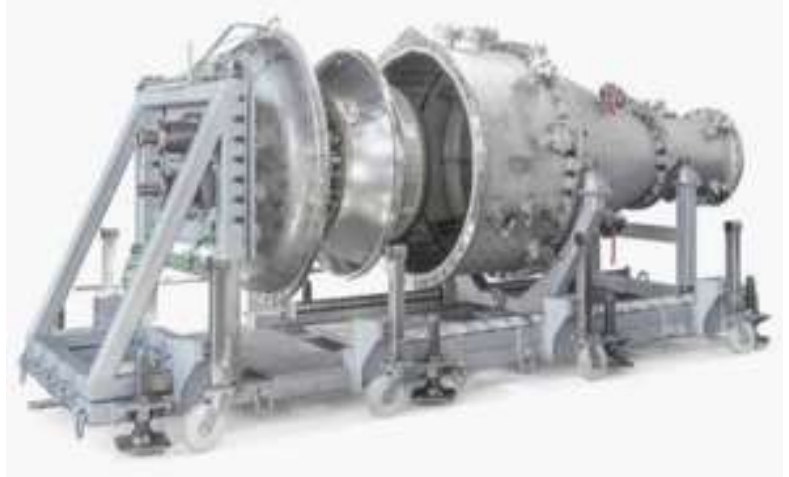

Fig. 47: SABRE engines are capable of Mach 5.4 in airbreathing mode and Mach 25 in rocket mode for space flight

Current jet engines can only power a vehicle up to Mach 3, three times the speed of sound, Reaction Engines explains on their website. A Mach number is a dimensionless quantity representing the ratio of flow velocity past a boundary to the local speed of sound.

SABRE engines are capable of Mach 5.4 in airbreathing mode and Mach 25 in rocket mode for space flight (Fig. 47).

"They are simply going to revolutionize the way we travel around the globe and into orbit," said Reaction Engines.

"Like jet engines, SABRE can be scaled in size to provide different levels of thrust for different applications which are crucial to our success - it's going to enable a whole generation of air and space vehicles."

Soon we will be able to forget about fuel tanks and batteries or accumulators, thanks to a new concept of the electric jet that uses air friction (friction of the ship with air) in order to generate energy. Instead of fossil fuels or large, bulky, heavy batteries, the Eather One will be 
powered by air friction over the wings and frame. This type of renewable energy on demand is a radical proposal (Fig. 48).

While the latest trend in business aviation is the creation of the next generation of electric and hybrid aircraft, a new type of space race could emerge if physics actually supports the theory behind Eather One.

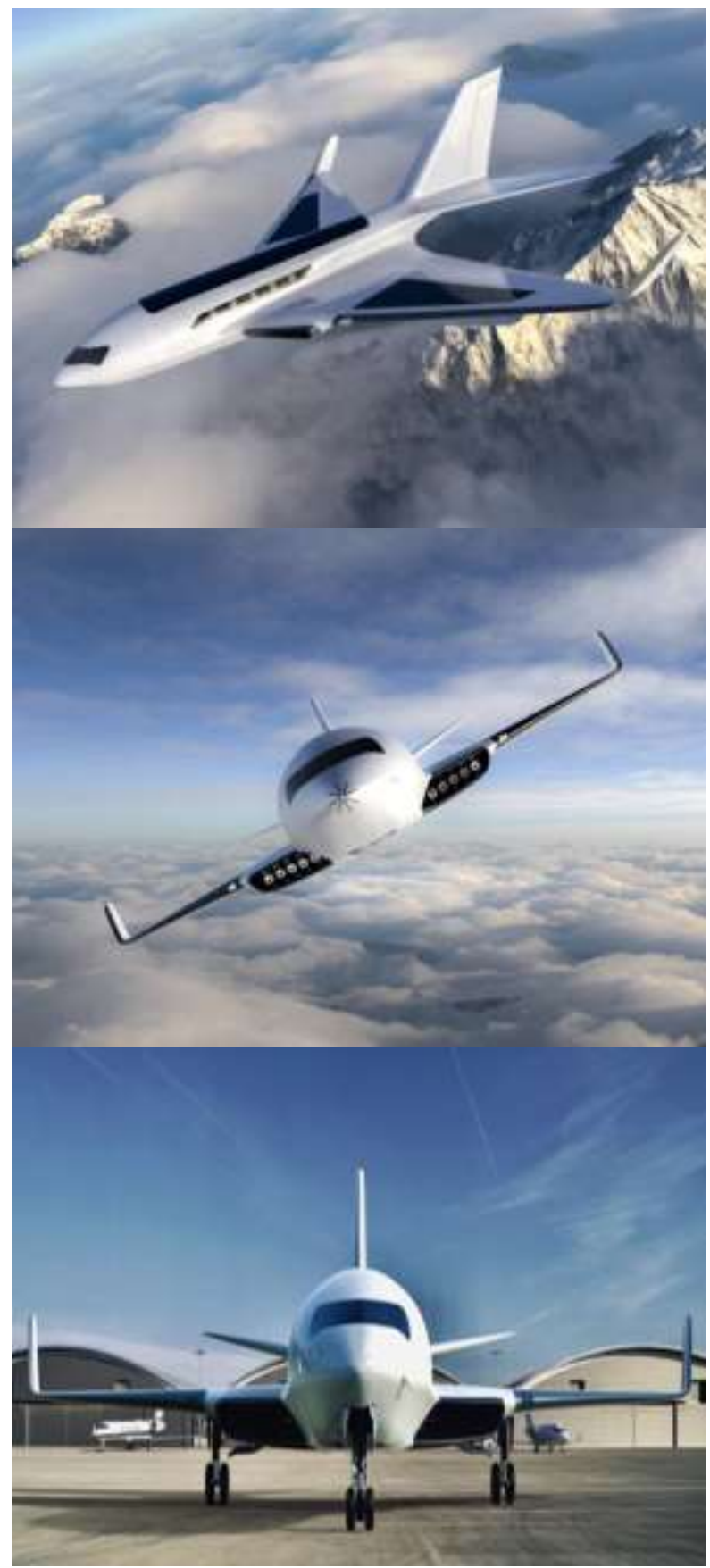

Fig. 48: Eather one will be powered by air friction over the wings and frame. This type of renewable energy on demand is a radical proposal
Designer Michal Bonikowski's concept is probably four or five generations ahead of the current way of thinking, but Bonikowski told Robb Report that he was inspired by Airbus' recent Maveric concept. "The unique design of the aircraft helps reduce traction while providing more cabin space," he said. "I've been thinking about this a lot lately and I wonder what could happen if a big company wanted to create an electric plane."

What came with the Warsaw designer is potentially revolutionary. Eather One uses air friction and high jet speed as the main source of renewable energy on demand.

Although it looks like a future aircraft, the main difference between Eather One and contemporary hybrid aircraft are winged triboelectric nanogenerators. Nanogenerators convert mechanical energy directly into electricity. The aircraft does not need large tanks or batteries, because it will generate electricity from the air molecules in the troposphere and stratosphere.

As Eather One travels at high speeds, Bonikowski's idea is to capitalize on the friction generated by the vibrations inside the aircraft and the bending of the wings. The converted energy will power the electric motors and recharge the batteries. This light source means that the Eather One will require smaller battery packs than aircraft that rely on the stored battery.

China briefly presents a new special, secret, prototype with UFO shapes, with special capabilities (Fig. 49).

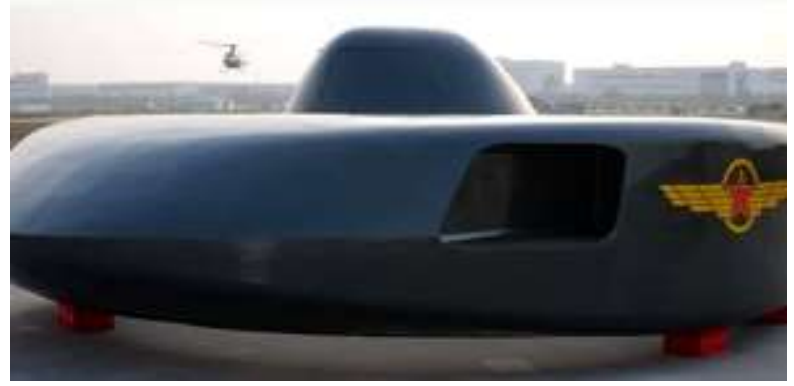

Fig. 49: Weirdest is e new aircraft. China briefly presents a new special, secret, prototype with UFO shapes, with special capabilities

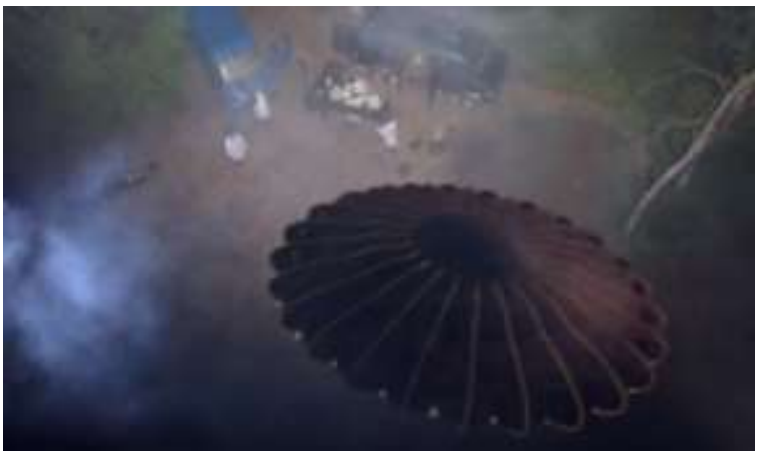

Fig. 50: A top secret US laser aircraft 
Flight of the future is science fiction or a reality? Laser aircraft will become normal in the future, flying at the speed of light, or very close to it, so that later this limit can be exceeded, the speed of movement becoming much higher than that of light, which will become only a lower limit from which space ships will accelerate, traversing galaxies at superluminal speeds. In Fig. 50 one can see a laser aircraft.

\section{Discussion}

Areas of innovation associated with progressive changes in commercial airline products and technology:

1. Application of the latest aircraft in the world of practice and maintenance technologies during the operation of previously mastered VLines. For example, the company is the first to start operating a new type of custom-made aircraft with increased comfort when flying on traditional routes. Additional services on site: Hotels, car rental, comfortable lounges at the airport, etc.

2. Applying the latest technologies in the world for aircraft and passenger services on new lines for the airline. The airline, having a technological advantage, is gaining positions in a new market

3. Application of new aircraft to airline and service technologies on controlled airlines. The airline is modernizing its fleet of aircraft based on new aircraft technologies and services and applying them to its traditional routes, thus creating a visible difference in product quality and distracting customers from competitors

4. Partial improvements and modernization of aircraft, technological basis during flights on traditional routes; For example, re-equipping aircraft with new engines, installing anti-collision air systems, satellite navigation, improving aircraft programming, ensuring flight connections, providing a customer with a package of services, changing the appearance of the cabin, etc.

\section{Choosing an Innovative Strategy for the Airline}

Innovative activity (ID) is a strategic area for increasing the airline's competitiveness associated with the commercial use of new equipment, technologies and the intellectual potential of staff. Innovations allow the formation of new market segments (niche markets) due to the improved or unique characteristics of the transport product, as well as the reduction of its cost.

The characteristics of the airline ID are: The absence of the experimental design work (R\&D) stage associated with the development of aircraft; airlines operate existing aircraft, avionics, reservation and sales systems and other technical means, which are developed by companies specializing in research and development; specific functional focus: Airlines provide services for the transport of passengers, freight, mail and diversify their activities; the high cost of new aircraft combined with the airline's limited financial resources; large leasing and rental relationships; significant fluctuations in the air transport market, high level of competition. The complexity, high cost and risky nature of the ID require its scientific organization. The development of methodological bases for the organization of the airline ID is relevant, taking into account the principles of organization theory, the use of the practical experience of the operating aeronautical enterprises.

The innovation strategy can be chosen based on the assessment of the airline's competitiveness. Strategic choice options allow the airline to respond flexibly to fluctuations in the air transport market, to pursue a sound technical policy and to quickly seek reserves to reduce costs.

Creating an environment conducive to innovation should be a necessary element of organizational culture. A similar environment occurs when: Leadership is receptive to new ideas; working contacts between employees are encouraged; when problems are solved and new developments are made, working groups (project teams) are created from the employees of the different departments; staff development is encouraged.

In adopting a strategy, management must consider four factors.

Risk. What level of risk does the company consider acceptable for each of its decisions?

Knowledge of past strategies and the results of their application. This will allow the company to develop new ones more successfully.

The time factor ... Good ideas often fail because they were proposed at the wrong time.

Response to owners ... The strategic plan is developed by company managers, but often owners can apply strong pressure to change it. The management of the company should take this factor into account.

\section{Innovative Approaches to Airline Rebranding}

Rebranding It is a change in brand positioning to increase consumer interest and loyalty. The main strategic objective of rebranding is to achieve the long-term profitability of the company's activities on the market.

It's rebranding, as it is also called "restart", is primarily associated with a change in the brand's ideology. The need for rebranding arises when it is important to preserve the essence of the product, but change, for example, its emotional component, increase its relevance and declare its competitive advantages. It is important to remember that rebranding if you do not take into account the nuances of consumer relationships with an existing brand, may not work. At the same time, a successful rebranding allows the company to reach a 
new level of development. While working on relaunching the brand, we consider the product and its conceptual component from different angles, find something new in the family and offer customers a balanced solution that will help both attract new customers and maintain the interest of existing ones.

The specifics of rebranding as directions for the development of product promotion strategies in connection with the communication activity of airlines, which made it possible, first of all, to determine the most acceptable method for creating an airline name - the reference method; second, to disclose the brand structure of the air carrier, including the national profile picture, services, consumer, founder/leader, staff, internal airline image, visual, social and business image; justified the need for an integrated approach to brand promotion.

The rebranding of the airline can be based not only on the desire to obtain a strong brand that is understandable both in Russia and abroad, the formation of internationality and the "brilliance" of marketing communications, business expansion and increased capitalization but also the avoidance of a negative image.

\section{Successful Rebranding Step}

McKinsey offers his rebranding plan, which consists of three sequential steps. The brand rebranding steps described below will help to perform the correct analysis and determine the realistically achievable position for the company.

Rebranding may include, in particular, the modification or adjustment of the following brand attributes (both individually and collectively):

- Changing the positioning of prices (for example, moving from an average price niche to a premium one)

- Changing the positioning platform (when the main value of the brand that is communicated to the consumer changes)

- Changing the brand architecture (or the brand-subbrand ratio in the company's brand portfolio)

- Reorientation towards a different target audience (for example, expanding the target audience or, conversely, moving to niche positioning)

- Name change (in the case of domestic companies, it is often dictated by the desire to get rid of associations with the legacy of the Soviet era)

- Design change (visually, allows you to create an updated brand image with target partners)

At the same time, rebranding can involve both a complete change of the listed attributes and maintaining continuity with the existing image.

It is advisable to maintain continuity when the accumulated potential of the brand has a "positive charge", it is recognized and loved by consumers. In this case, the task of rebranding is to improve the image, adding the necessary target associations to the brand. For example, to make it more modern, more friendly, or more innovative, while maintaining recognition.

Thus, by combining product innovation, reaching new markets and repositioning products, the company transforms the traditional life cycle curve into a shell curve. The effectiveness of this process lies not only in prolonging the life of a product on the market and preventing a recession but also in increasing sales at each innovation 'comb'. At the same time, consumer loyalty to the common corporate brand increases, giving it an innovative image, which means that demand for other product groups of the manufacturer is stimulated.

Of particular interest in terms of innovative marketing is product repositioning technology, which is relatively new and the most dynamic in development. In general, this process means a new positioning of an old product that is not subject to change. Obviously, this innovation is the least expensive, characterized by a low degree of risk, but it requires marketers a good knowledge of the market and the ability to predict consumer preferences.

There are at least three main methods of repositioning:

1. highlighting new areas of application

2. offering a new functional image

3. focusing on certain properties that have not been previously identified

\section{Highlighting New Areas of Application}

Expanding the product range is a popular innovation for many FMCG product manufacturers. When consumers have developed brand loyalty, but the branded product line does not have a specific product to meet new needs, the company repositioned the old product as being able to meet those needs.

The activities of the innovation plan include works that include: (1) Retraining of specialists; (2) the necessary structural changes of the airline; (3) preparation of the production base (buildings, structures, technological equipment); (4) clarification of the characteristics of the material and technical support for the operation of the new TA; (5) identification and consideration of the specific factors of the airline's activities that are essential for the development of a new aircraft (base characteristics, technical equipment and climatic conditions). When mastering new Aircraft (TA) equipment for industry, aviation undertakings, which will be the first to receive it, are expected to participate in state tests, evaluating and agreeing on operational documentation that develops 85, analyzing aircraft reliability based on test results and developing appropriate measures based on test results. 
Striving to become closer to the consumer, many companies today decide to renew their corporate identity. At the moment, rebranding is dominated by the same trends as in graphic and web design. This is minimalism, fashionable "flat style", visual puzzles when creating logos, laconicism. Most companies that changed in 2014 focused on mobile users because the presence of a brand on the Internet today has a strong advertising effect. As a result, a lot of interesting logos have appeared, which show well what trends will dominate the rebranding next year.

Examples of: American Airlines is a major airline that serves customers around the world. The air carrier is constantly evolving, investing heavily in modernization and technological upgrades. The old company logo had been used for 40 years and no longer matched the company's image. The new logo was supposed to symbolize what American Airlines is proud of the innovation, excellent services, commitment to progress. The change in corporate identity has led to passengers starting to use the services of an airline more often, which has immediately affected the company's profits. The media reaction was also positive the rebranding of American Airlines, in the opinion of many, was only beneficial for the company.

Vivity Labs, which owns the Fit Brains brand, has decided to change its brand in connection with the need to strengthen its market position. The old Fit Brains logo is very outdated and for a mobile app, which is Fit Brains, this is unacceptable. The rebranding was intended to ensure good image recognition and the new logo had to be moderately frivolous while leaving the impression of brand reliability. Following the rebranding, Fit Brains significantly increased the number of users who installed the mobile application. In the first half of 2013, Fit Brains was used by about one and a half million people. After the change of corporate identity, the user base of the application exceeded 4 million people - a success without a doubt.

\section{Management of Innovative Activities in the Airline}

Innovation management should occupy the same place in the management of an aviation enterprise as the management of production, marketing, finance, personnel.

The development and implementation of innovations in the airline should be carried out taking into account the requirements of the Air Code of the Russian Federation, the Manual on the technical operation and repair of aviation equipment in Russian civil aviation (INTERACT GA), Licensing Regulations for related to the implementation of the transport process in air transport in the Russian Federation and other regulatory documents.

The implementation of an innovative project and its management are one-time, unique, as opposed to the permanent activity of transport management.

Levels of management and types of innovation project planning:
- Feasibility Study (FS) - a document that provides information from which the opportunity (or inability) to create a product or service is derived

The development of the production of airport services related to air traffic is carried out in the following areas:

- Development of new services (reception and dispatch of new aircraft; development of international traffic services; the opening of new airlines; provision of intermediate landings of aircraft flying on new air routes; reception of business aircraft)

- Improving the quality and conditions for the provision of traditional services (increasing the frequency of aircraft departures; reducing the time for aircraft maintenance, passing passenger formalities; bringing international passenger services; increasing airport classification; reducing airport charges)

- Increasing the volume of traditional services (increasing the intensity of aircraft traffic through the airport)

The main means of solving the above problems is the development of the airport's (production) operating system, which is done in the following ways:

- Mastering and expanding the use of certain types of new equipment and technologies, improving production organization, introducing managerial innovations, developing information technologies

- Creation and acquisition of industrial intellectual property objects (licenses, patents, scientific and technical documentation, inventions, rationalization proposals, etc.)

- Implementation of large-scale forms of reproduction of fixed assets: New construction, extension, reconstruction, technical re-equipment

The aviation industry today can be attributed to key areas for the development of the domestic economy. The stable functioning of the aeronautical industry is a vector that creates all the prerequisites for the development of an entire complex of high-tech enterprises, as well as their preservation. It provides "intellectualization" of the GDP structure, the development of the export of progressive products of the machine-building complex, as well as the replacement of imports in key product segments.

In addition, the aeronautical industry plays one of the main functions from a social point of view, taking into account the related industries, allowing an increase in the number of new skilled jobs at production sites, in research and development, in universities and educational institutions. specialized secondary education. The main segments of the industry are aircraft construction, helicopter construction, engine construction and aircraft instrument construction. 
One of the most important developments of the Technodinamika operation is an aircraft movement system that uses an electric drive of the landing gear wheels for regional and short-haul aircraft.

An Accident-resistant fuel System (ATS) can also be attributed to unique products. Taking into account the latest European aviation standards, which include a significant increase in safety requirements, crashresistant fuel systems should be used in all state-of-theart transport and passenger helicopters. The solution of the operation allows ensuring the safety of the machines against the possible consequences in conditions of difficult landing.

Technodinamika is the first farm to create such a system and confirm its high-performance characteristics. During the tests, a series of discharges were carried out, during which the fuel tank models successfully confirmed the effectiveness of the development. Successful tests of other units of the system were also performed. The uniqueness of the ATS lies in the fact that, in emergency situations, the fuel tanks maintain their integrity and the ruptures in connections appear in specialized elements that prevent fuel leaks. Fuel tanks, designed with innovative materials, are airtight and puncture-resistant, while PTFE hoses and titanium fittings can withstand high temperatures and pressures.

In addition, one of the newest systems created by Technodinamika Holding is the neutral gas (LPG) system; can be used on any type of aircraft. The solution fully complies with requirements, including Russian and international standards and security requirements. The system allows it to create an inert environment and prevent the formation of flammable fuel vapors in the tanks of the fuel system by reducing the oxygen content.

The use of a system with a diaphragm air separator module provides a reduction in its weight. If we compare the solution with a neutral gas cylinder system, then the decrease in weight characteristics reaches 2-3 times. It also reduces system maintenance time during operation.

The neutral gas system with air separation mode requires no pre-flight maintenance. It can be installed on different types of aircraft, while the operation of the system in automatic mode does not distract the flight crew. The installation of a neutral gas system developed by Technodinamika ensures the compliance of aircraft with global safety standards.

The aviation industry is another branch of the hightech sector of the economy, which has significant potential for innovative development. The companies of the Technodinamika holding company successfully achieve innovative evolutions in the aircraft industry, implementing the Industry 4.0 strategy in all stages of their activity and annually completing the portfolio with new high-quality projects.

\section{Conclusion}

Aircraft manufacturers are constantly concerned with modifying their aircraft and building other new models that meet customer requirements as much as possible, but at the same time lead to reductions in total fuel consumption used in flight, to reduce pollution due to flights and the negative effects on planetary ecosystems, as well as the increase in the quality and safety of air travel.

For these reasons, new and new models, concepts and then new aircraft are constantly appearing, which today integrate very quickly in air traffic, an important additional requirement being that of ensuring increased autonomy and achieving high travel speeds to shorten real travel times especially on very long and tiring routes.

The introduction of hydrogen fuel is today a major requirement that must be solved correctly and in a timely manner by major aircraft manufacturers, in order to eliminate the emissions produced by aircraft.

Sooner or later, hydrogen will become the number one fuel for aviation and aerospace, whether it is burned or used as a raw material to obtain nuclear fusion energy directly on the spacecraft. Hydrogen is practically the future source of energy and the key to successfully solving the energy problem in aerospace and aviation but also in other industrial and civil fields.

EADS has thought of building the Voltaire project with two large batteries, each with a very high density, which is positioned in the hold so that they can be easily changed when the plane arrives at an airport. The discharged batteries will then be returned to a charging station in the same way that cargo and luggage are removed from an aircraft - a set of fully charged batteries to be replaced so that the aircraft does not waste time waiting to charge the batteries, so they are very easy to replace, wherever the plane will land. The rear propulsion system together with electric motors achieves great fuel economy, eliminates the huge noises of propulsion on classic fuels, fossil fuels, eliminates environmental pollution with already known classic pollutants that have completely destroyed nature's ecosystems thus achieving all dreams of humanity to fly smoothly without noise and noxious substances, without environmental pollution, without stress and in great safety, with a much high quality of flight. The proposed system aims to bring with it the success that the industry has had in the last 10 years and the batteries they need $1000 \mathrm{Wh} / \mathrm{kg}$ - in no more than 20 years, which would completely change the way they fly.

Although it looks like a future aircraft, the main difference between Eather One and contemporary hybrid aircraft are winged triboelectric nanogenerators. Nanogenerators convert mechanical energy directly into 
electricity. The aircraft does not need large tanks or batteries, because it will generate electricity from the air molecules in the troposphere and stratosphere.

As Eather One travels at high speeds, Bonikowski's idea is to capitalize on the friction generated by the vibrations inside the aircraft and the bending of the wings. The converted energy will power the electric motors and recharge the batteries. This light source means that the Eather One will require smaller battery packs than aircraft that rely on the stored battery.

\section{Acknowledgement}

This text was acknowledged and appreciated by Dr. Veturia CHIROIU Honorific member of Technical Sciences Academy of Romania (ASTR) Ph.D. supervisor in Mechanical Engineering.

\section{Funding Information}

Research contract: Contract number 36-5-4D/1986 from 24IV1985, beneficiary CNST RO (Romanian National Center for Science and Technology) Improving dynamic mechanisms internal combustion engines.

\section{!All these matters are copyrighted!}

Copyrights:

- New Aircraft (New Ionic or Beam Engines): no. 548 of 22-04-2010 [cgiywDssin], Aerospace Engineering

- Some Few Specifications About the Doppler Effect to the Electromagnetic Waves: 636 of 28-05-2010 [iEtcaouxxA], physics

- Presenting an Atomic Model and Some Possible Applications in LASER Field: nr. 639 of 29-052010 [yncngrotfo], physics

- $\quad$ Some Applications in LASER Field: no. 718 of 0907-2010 [xeujouincC], physics

- The Energies of Today and Tomorrow: nr. 819 of 30-09-2010 [kbHquxwykr], energy engineering

- Obtaining Energy by the Annihilation of the Matter with Antimatter - The Battle for Energy: nr. 1068 of 13.03.2011 [GfEqpGDzeh], Energy Engineering

\section{Ethics}

This article is original and contains unpublished material. Author declares that are not ethical issues and no conflict of interest that may arise after the publication of this manuscript.

\section{References}

Anderson, S. B. (1997). Historical Overview of V/STOL Aircraft Technology. NTRS - NASA Technical Reports Server.
Antonescu, P., \& Petrescu, F. (1985). Analytical method of synthesis of cam mechanism and flat stick. In Proceedings of the 4th International Symposium on Theory and Practice of Mechanisms, (TPM'89), Bucharest.

Antonescu, P., \& Petrescu, F. (1989). Contributions to cinetoelastodynamic analysis of distribution mechanisms.

Antonescu, P., Oprean, M., \& Petrescu, F. (1985a). Contributions to the synthesis of oscillating cam mechanism and oscillating flat stick. In Proceedings of the 4th International Symposium on Theory and Practice of Mechanisms,(TPM'85), Bucharest.

Antonescu, P., Oprean, M., \& Petrescu, F. (1985b). At the projection of the oscillate cams, there are mechanisms and distribution variables. In Proceedings of the V-Conference for Engines, Automobiles, Tractors and Agricultural Machines, IEngines and Automobiles, (AMA'85), Brasov.

Antonescu, P., Oprean, M., \& Petrescu, F. (1986). Projection of the profile of the rotating camshaft acting on the oscillating plate with disengagement. In Proceedings of the 3rd National Computer-aided Design Symposium in the field of Mechanisms and Machine Parts, (MMP'86), Brasov.

Antonescu, P., Oprean, M., \& Petrescu, F. (1987). Dynamic analysis of the cam distribution mechanisms. In Proceedings of the 7th National Symposium on Industrial Robots and Space Mechanisms, (RSM'87), Bucharest.

Antonescu, P., Oprean, M., \& Petrescu, F. (1988). Analytical synthesis of Kurz profile, rotating the flat cam. Mach, Build. Rev.

Antonescu, P., Petrescu, F., \& Antonescu, O. (1994). Contributions to the synthesis of the rotating cam mechanism and the tip of the balancing tip.

Antonescu, P., Petrescu, F., \& Antonescu, D. (1997). Geometrical synthesis of the rotary cam and balance tappet mechanism. Bucharest, 3, 23-23.

Antonescu, P., Petrescu, F., \& Antonescu, O. (2000a). Contributions to the synthesis of the rotary disc-cam profile. In Proceedings of the 8th International Conference on the Theory of Machines and Mechanisms, (TMM'00), Liberec, Czech Republic (pp. 51-56).

Antonescu, P., Petrescu, F., \& Antonescu, O. (2000b). Synthesis of the rotary cam profile with balance follower. In Proceedings of the 8th Symposium on Mechanisms and Mechanical Transmissions, (MMT'00), Timişoara (pp. 39-44).

Antonescu, P., Petrescu, F., \& Antonescu, O. (2001). Contributions to the synthesis of mechanisms with rotary disc-cam. In Proceedings of the 8th IFToMM International Symposium on Theory of Machines and Mechanisms, (TMM'01), Bucharest, ROMANIA (pp. 31-36). 
Aversa, R., Petrescu, R. V., Apicella, A., \& Petrescu, F. I. (2017a). Nano-diamond hybrid materials for structural biomedical application. American Journal of Biochemistry and Biotechnology, 13(1), 34-41.

Aversa, R., Petrescu, R. V., Akash, B., Bucinell, R., Corchado, J., Chen, G., ... \& Petrescu, F. I. (2017b). Kinematics and forces to a new model forging manipulator. American Journal of Applied Sciences, 14(1), 60-80.

Aversa, R., Petrescu, R. V., Apicella, A., Petrescu, F. I., Calautit, J. K., Bucinell, R., \& Akash, B. (2017c). Something about the $\mathrm{V}$ engines design. American Journal of Applied Sciences, 14(1), 34-52.

Aversa, R., Parcesepe, D., Petrescu, R. V., Berto, F., Chen, G., Petrescu, F. I., ... \& Apicella, A. (2017d). Processability of bulk metallic glasses. American Journal of Applied Sciences, 14(2), 294-301.

Aversa, R., Petrescu, F. I., Petrescu, R. V., \& Apicella, A. (2016a). Biomimetic finite element analysis bone modeling for customized hybrid biological prostheses development. American Journal of Applied Sciences, 13(11), 1060-1067.

Aversa, R., Parcesepe, D., Petrescu, R. V. V., Chen, G., Petrescu, F. I. T., Tamburrino, F., \& Apicella, A. (2016b). Glassy amorphous metal injection molded induced morphological defects.

Aversa, R., Petrescu, R. V., Petrescu, F. I., \& Apicella, A. (2016c). Smart-factory: Optimization and process control of composite centrifuged pipes. American Journal of Applied Sciences, 13(11), 1330-1341.

Aversa, R., Tamburrino, F., Petrescu, R. V., Petrescu, F. I., Artur, M., Chen, G., \& Apicella, A. (2016d). Biomechanically inspired shape memory effect machines driven by muscle like acting NiTi alloys. American Journal of Applied Sciences, 13(11), 1264-1271.

Ayiei, A. (2020). The Use of Eye Tracking in Assessing Visual Attention. Journal of Aircraft and Spacecraft Technology. 4, 117-124.

Babu, K. V., Rao, A. S., Kumar, K. N., \& Rao, M. V. (2019). Spectral and luminescence properties of manganese doped sodium lead alumino borosilicate glass system. Journal of Aircraft and Spacecraft Technology, 3(1), 248-255.

Babu, K. V., Subba Rao, A., Madhuri, V., \& Suresh, K. (2020). White light generation in Dy3+-doped sodium lead alumino borosilicate glasses for WLED applications. Journal of Aircraft and Spacecraft Technology. 4(1), 39-47.

Brewer, G. D. (1991). Hydrogen aircraft technology. CRC press.

Brischetto, S., \& Torre, R. (2020). Honeycomb Sandwich Specimens Made of PLA and Produced Via 3D FDM Printing Process: An Experimental Study.
Cao, W., Ding, H., Zi, B., \& Chen, Z. (2013). New structural representation and digital-analysis platform for symmetrical parallel mechanisms. International Journal of Advanced Robotic Systems, 10(5), 243.

Chaudhary, S., \& Kumar, A. (2019). Control of twin rotor MIMO system using PID and LQR controller. Journal of Aircraft and Spacecraft Technology, 3(1), 211-220.

Chilukuri, D., Yi, S., \& Seong, Y. (2019). Computer Vision for Vulnerable Road Users using Machine Learning. Journal of Mechatronics and Robotics. 3, 33-41.

Council of the European Union, Policies (2018). Drone: aviation safety reform in the EU. https://www.consilium.europa.eu/ro/policies/drones/

Dekkata, S. C., \& S. Yi, (2019). Improved Steering and Adaptive Cruise Control for Autonomous Vehicles Using Model Predictive Control. Journal of Mechatronics and Robotics. 3, 378-388.

de Lima, M. S. F., de Mota Siqueira, R. H., de Carvalho, S. M., \& Abdalla, A. J. (2019). Hardening Effects of In-Situ Aging for a Laser Welded Maraging Steel.

de Mota Siqueira, R. H., Atilio, I., de Andrade Ferreira, C. C., de Carvalho, S. M., \& de Lima, M. S. F. (2020). Fiber Laser Beam Welding Between Niobium and Titanium. Journal of Aircraft and Spacecraft Technology. 4(1), 21-25.

Dong, H., Giakoumidis, N., Figueroa, N., \& Mavridis, N. (2013). Approaching behaviour monitor and vibration indication in developing a General Moving Object Alarm System (GMOAS). International Journal of Advanced Robotic Systems, 10(7), 290.

Dwivedi, A., Kumar, D., \& Tiwari, N. (2019a). A Review on Electric Traction using WE System.

Dwivedi, A., Rajbhar, P., \& Tiwari, N. (2019b). Long Distance Power Transfer Technique: A Review.

Eissa, M. A., Darwish, R. R., \& Bassiuny, A. M. (2019). New Model-Based Fault Detection Approach using Black Box Observer.

Eremia, C. (2020). Has the era of air drone wars finally settled? Defense and Security Monitor. https://monitorulapararii.ro/epoca-razboaielordronelor-aeriene-s-a-instalat-definitiv-1-31794

Fahim, S. R., Dey, S., Rashiduzzaman, M., Sarker, S. K., Badal, F. R., \& Das, S. K. (2019). Development of an Android Recognition Open-Loop Tracking Control of Writing Robotic Arm. Journal of Mechatronics and Robotics. 3, 521-533.

Franklin, D. J. (1930). Ingenious mechanisms for designers and inventors.

García, A. G. (2020). Asymptotic Stability of UnicycleLike Robots: The Bessel's Controller. 
Garfo, S., Muktadir, M. A., \& Yi, S. (2020). Defect Detection on 3D Print Products and in Concrete Structures Using Image Processing and Convolution Neural Network.

Hanrahan, J. (2014). Drone Attack Survival Guide could save your life. Vice Media Group https://www.vice.com/ro/article/53p4xz/ghidul-desupravietuire-a-atacurilor-cu-drone-ti-ar-puteasalva-viata

El Hassouni, B., Haddi, A., \& Amrani, A. G. (2019). Critical Study of Several MPPT Techniques for Photovoltaic Systems. Journal of Mechatronics and Robotics. 3, 269-279.

He, B., Wang, Z., Li, Q., Xie, H., \& Shen, R. (2013). An analytic method for the kinematics and dynamics of a multiple-backbone continuum robot. International Journal of Advanced Robotic Systems, 10(1), 84.

Hertel, C. (2017). 10 questions you always wanted to ask a pilot. https://www.vice.com/ro/article/ne7va8/intrebaripilot-curiozitati

Kisabo, A. B., Adebimpe, A. F., \& Samuel, S. O. (2019a). Pitch Control of a Rocket with a Novel LQG/LTR Control Algorithm.

Kisabo, A. B., Nwokolo, N., Adebimpe, A. F., \& Samuel, S. O. (2019b). Novel Approach for Characterizing Solid Rocket Motor (SRM).

Kisabo, A. B., \& Adebimpe, A. F. (2019). State-Space Modeling of a Rocket for Optimal Control System Design. In Ballistics. IntechOpen.

Kortam, M. A., Tolba, F. A., \& Abdelkader Hassen, A. M. (2018). Development of a Mechatronic Control System for a Mechanical Fuel Injection System of a Four-Cylinder Automotive Diesel Engine By using Matlab and Simulink. Journal of Mechatronics and Robotics. 2, 60-71.

Kumar, R. V. N., \& Sreenivasulu, R. (2019). Inverse Kinematics (IK) Solution of a Robotic Manipulator using PYTHON. Journal of Mechatronics and Robotics. 3, 542-551.

Komakula, S. A. (2019). Optimization of Inverse Kinematic Solution of a T4R Robotic Manipulator.

Kosambe, S. (2019a). NASA's exploration missions to the red planet. Journal of Aircraft and Spacecraft Technology. 3(1), 154-171.

Kosambe, S. (2019b). Mission Shakti aka Project XSV1: India's First Anti-Satellite Test (ASAT).

Kosambe, S. (2019c). Overview of Space Debris Mitigation Activities in ISRO.

Kosambe, S. (2019d). Chandrayaan-2: India's second lunar exploration mission. Journal of Aircraft and Spacecraft Technology, 3(1), 221-236.

Langston, L. S. (2016). Hot Plates. Mechanical Engineering, 138(03), 42-47.
Langston, L. S. (2015). Gas Turbines-Major Greenhouse Gas Inhibitors. Mechanical Engineering, 137(12), 54-55.

Lee, B. J. (2013). Geometrical derivation of differential kinematics to calibrate model parameters of flexible manipulator. International Journal of Advanced Robotic Systems, 10(2), 106.

Lin, W., Li, B., Yang, X., \& Zhang, D. (2013). Modelling and control of inverse dynamics for a 5DOF parallel kinematic polishing machine. International Journal of Advanced Robotic Systems, 10(8), 314.

Liu, H., Zhou, W., Lai, X., \& Zhu, S. (2013). An efficient inverse kinematic algorithm for a PUMA560-structured robot manipulator. International Journal of Advanced Robotic Systems, 10(5), 236.

Matthews, M. T., \& Yi, S. (2019). Adaptive and Neural Network Based Control of Pitch of Unmanned Aerial Vehicles.

Mishra, A. (2020a). Image Processing of Friction Stir Welded 6060-T5 Aluminum Alloy Joint.

Mishra, A. (2020b). Machine Learning Approach for Defects Identification in Dissimilar Friction Stir Welded Aluminium Alloys AA 7075-AA 1100 Joints.

Mishra, A., \& Sarawagi, R. (2020). Local Binary Pattern for the Evaluation of Surface Quality of Dissimilar Friction Stir Welded Ultrafine Grained 1050 and 6061-T6 Aluminium Alloys. Journal of Mechatronics and Robotics. 4, 106-112.

Nacy, S. M., \& Nayif, A. A. (2018). Effect of Object Size and Location on Contact Forces and Grasping Stability for an Underactuated Robotic Manipulator. Journal of Mechatronics and Robotics. 2, 72-84.

Oni, M. O., \& Jha, B. K. (2019). Heat Generation/absorption effect on natural convection flow in a vertical annulus with time-periodic boundary conditions. Journal of Aircraft and Spacecraft Technology, 3(1), 183-196.

Padula, F., \& Perdereau, V. (2013). An on-line path planner for industrial manipulators. International Journal of Advanced Robotic Systems, 10(3), 156.

Perumaal, S. S., \& Jawahar, N. (2013). Automated trajectory planner of industrial robot for pick-andplace task. International Journal of Advanced Robotic Systems, 10(2), 100.

Petrescu, F., \& Petrescu, R. (1995a). Contributions to optimization of the polynomial motion laws of the stick from the internal combustion engine distribution mechanism. Bucharest, 1, 249-256.

Petrescu, F., \& Petrescu, R. (1995b). Contributions to the synthesis of internal combustion engine distribution mechanisms. Bucharest, 1, 257-264. 
Petrescu, F., \& Petrescu, R. (1997a). Dynamics of cam mechanisms (exemplified on the classic distribution mechanism). Bucharest, 3, 353-358.

Petrescu, F., \& Petrescu, R. (1997b). Contributions to the synthesis of the distribution mechanisms of internal combustion engines with a Cartesian coordinate method. Bucharest, 3, 359-364.

Petrescu, F., \& Petrescu, R. (1997c). Contributions to maximizing polynomial laws for the active stroke of the distribution mechanism from internal combustion engines. Bucharest, 3, 365-370.

Petrescu, F., \& Petrescu, R. (2000a). Synthesis of distribution mechanisms by the rectangular (Cartesian) coordinate method. University of Craiova, Craiova.

Petrescu, F., \& Petrescu, R. (2000b). The design (synthesis) of cams using the polar coordinate method (triangle method). University of Craiova, Craiova.

Petrescu, F., \& Petrescu, R. (2002a). Motion laws for cams. In Proceedings of the International Computer Assisted Design, National Symposium with Participation,(SNP'02), Braşov (pp. 321-326).

Petrescu, F., \& Petrescu, R. (2002b). Camshaft dynamics elements. In Proceedings of the International Computer Assisted Design, National Participation Symposium,(SNP'02), Braşov (pp. 327-332).

Petrescu, F., \& Petrescu, R. (2003). Some elements regarding the improvement of the engine design. In Proceedings of the National Symposium, Descriptive Geometry, Technical Graphics and Design,(GTD'03), Braşov (pp. 353-358).

Petrescu, F. I., \& Petrescu, R. V. (2005a). The cam design for a better efficiency. Available at SSRN 3076805 .

Petrescu, F. I., \& Petrescu, R. V. (2005b, September). Contributions at the Dynamic of Cams. In The Ninth IFTOMM International Symposium on Theory of Machines and Mechanisms.

Petrescu, F. I., \& Petrescu, R. V. (2005c). Determining the dynamic efficiency of cams. Available at SSRN 3076802.

Petrescu, F. I., \& Petrescu, R. V. (2005d). An original internal combustion engine. In The Ninth IFTOMM International Symposium on Theory of Machines and Mechanisms.

Petrescu, R. V., \& Petrescu, F. I. (2005e). Determining the mechanical efficiency of Otto engine's mechanism. Available at SSRN 3076804.

Petrescu, R. V., Petrescu, F. I., \& Popescu, N. (2007). Determining gear efficiency. Gear Solutions.

Petrescu, F., \& Petrescu, R. (2011a). Mechanical Systems, Serial and Parallel. Lulu. com.

Petrescu, F. I. T., \& Petrescu, R. V. (2011b). Trenuri planetare. Createspace Independent Pub, 104.
Petrescu, F. I., \& Petrescu, R. V. (2011c). Determination of the Mechanical Efficiency of the Gears. INGINERIA AUTOMOBILULUI, (19), 22-23.

Petrescu, F. I., \& Petrescu, R. V. (2012a). Kinematics of the planar quadrilateral mechanism.

Petrescu, F. I., \& Petrescu, R. V. (2012b). Mecatronicasisteme seriale si paralele.

Petrescu, F. I., \& Petrescu, R. V. (2013a). Cinematics of the 3R Dyad.

Petrescu, F. I., \& Petrescu, R. V. (2013b). Cams with high efficiency. Int. Rev. Mech. Eng, 7(4), 599-606.

Petrescu, F. I. T., \& Petrescu, R. V. (2013c). An algorithm for setting the dynamic parameters of the classic distribution mechanism. Int. Rev. Modell. Simulat, 6, 1637-1641.

Petrescu, F. I., \& Petrescu, R. V. (2013d). Dynamic synthesis of the rotary cam and translated tappet with roll. Engevista, 15(3).

Petrescu, F. I., \& Petrescu, R. V. (2013e). Forces and efficiency of cams. Int. Rev. Mech. Eng, 7(3), 507-511.

Petrescu, F. I. T., \& Petrescu, R. V. V. (2014a). High efficiency gear. Facta Universitatis, Series: Mechanical Engineering, 12(1), 51-60.

Petrescu, F. I., \& Petrescu, R. V. (2014b). Cam gears dynamics in the classic distribution. Independent Journal of Management \& Production (IJM\&P), 5(1).

Petrescu, F. I., \& Petrescu, R. V. (2014c). High efficiency gears synthesis by avoid the interferences. Independent Journal of Management \& Production (IJM\&P), 5(2).

Petrescu, F. I. T., \& Petrescu, R. V. (2014d). Balancing otto engines. Int. Rev. Mech. Eng, 8, 473-480.

Petrescu, F. I. T., \& Petrescu, R. V. (2014e). Machine equations to the classical distribution. Int. Rev. Mech. Eng, 8, 309-316.

Petrescu, F. I. T., \& Petrescu, R. V. (2014f). Forces of internal combustion heat engines. Int. Rev. Modell. Simulat, 7, 206-212.

Petrescu, F. I. T., \& Petrescu, R. V. (2014g). Determination of the yield of internal combustion thermal engines. Int. Rev. Mech. Eng, 8, 62-67.

Petrescu, F. I., \& Petrescu, R. V. (2014h). Cam Dynamic Synthesis. Al-Khwarizmi Engineering Journal, 10(1), 1-23.

Petrescu, F. I., \& Petrescu, R. V. (2016a). Parallel moving mechanical systems kinematics.

Petrescu, F. I., \& Petrescu, R. V. (2016b). Direct and inverse kinematics to the anthropomorphic robots.

Petrescu, F. I., \& Petrescu, R. V. (2016c). Dynamic cinematic to a structure 2R. GEINTEC Journal, 6(2).

Petrescu, F. I. T., \& Petrescu, R. V. V. (2019a). An algorithm to determining the gear efficiency to a simple planetary train. Independent Journal of Management \& Production, 10(5), 1392-1404. 
Petrescu, R. V., \& Petrescu, F. I. (2019b). StructuralTopological Synthesis of Space Mechanisms With Rods and Wheels. Independent Journal of Management \& Production (IJM\&P) v, 10.

Petrescu, F. I. T., \& Petrescu, R. V. V. (2019c). Application to rigid memory mechanisms of a variable internal dynamic damping model. Independent Journal of Management \& Production, 10(6), 1994-2022.

Petrescu, N., \& Petrescu, F. I. (2019d). The Yield of the Thermal Engines. Journal of Mechatronics and Robotics, 3, 215-236.

Petrescu, N., \& Petrescu, F. I. (2019e). Machine Motion Equations Presented in a New General Format. Journal of Mechatronics and Robotics, 3, 344-377.

Petrescu, N., \& Petrescu, F. I. (2019f). New About the Balancing of Thermal Motors. Available at SSRN 3445153.

Petrescu, F. I., Grecu, B., Comanescu, A., \& Petrescu, R. V. (2009, October). Some mechanical design elements. In The 3rd International Conference on Computational Mechanics and Virtual Engineering COMEC (pp. 29-30).

Petrescu, F.I.T., 2011. Teoria Mecanismelor si a Masinilor: Curs Si Aplicatii. 1st Edn., CreateSpace Independent Publishing Platform. ISBN-10: 1468015826. pp: 432.

Petrescu, F. I. T. (2012). Cold nuclear fusion. Plasma Phys. Fusion Technol. 44, 100-100.

Petrescu, R. V. V. (2019a). Giant success for NASA when the InSight probe has reached "safety" on Mars. Journal of Aircraft and Spacecraft Technology. 3(1), 1-10.

Petrescu, R. V. V. (2019b). Mars Could have Enough Molecular Oxygen to Support Life. Journal of Aircraft and Spacecraft Technology, 3(1), 11-23.

Petrescu, R. V. V. (2019c). About Boeing X-32. Journal of Aircraft and Spacecraft Technology, 3(1), 38-54.

Petrescu, R. V. V. (2019d). China Launches Its First Passenger Aircraft. Journal of Aircraft and Spacecraft Technology, 3, 64-77.

Petrescu, R. V. V. (2019e). NASA and the Conquest of Cosmic Space by Man. Journal of Aircraft and Spacecraft Technology, 3, 78-91.

Petrescu, R. V. V. (2019f). 'Defiant', A Today Unique Helicopter in the World. Journal of Aircraft and Spacecraft Technology, 3, 92-106.

Petrescu, R. V. V. (2019g). The TESS Satellite Will Search for Planets in the Vicinity of Our Solar System. Journal of Aircraft and Spacecraft Technology, 3, 107-118.

Petrescu, R. V. V. (2019h). Boeing's Autonomous Military Aircraft. Journal of Aircraft and Spacecraft Technology, 3, 138-153.
Petrescu, F. I. T. (2019i). About the nuclear particles' structure and dimensions. Computational Particle Mechanics, 6(2), 191-194.

Petrescu, R. V. (2019). About the Space Robots. Journal of Mechatronics and Robotics, 3, 1-32.

Petrescu, R. V. (2019k). Medical service of robots. Journal of Mechatronics and Robotics, 3, 60-81.

Petrescu, R. V. (20191). Dynamics at Classical Distribution. Journal of Mechatronics and Robotics, 3, 82-101.

Petrescu, R. V. (2019m). Time Factory. Journal of Mechatronics and Robotics, 3, 102-121.

Petrescu, R. V. (2019n). About Robotics, Mechatronics and Automation that Help us Conquer the Cosmic Space. Journal of Mechatronics and Robotics, 3, 129-155.

Petrescu, R. V. (2019o). Dynamic Models for Rigid Memory Mechanisms. Journal of Mechatronics and Robotics, 3, 156-183.

Petrescu, R. V. (2019p). Something about a Railbound Forging Manipulator. Journal of Mechatronics and Robotics, 3, 184-207.

Petrescu, R. V. (2019q). Face Recognition as a Biometric Application. Journal of Mechatronics and Robotics, 3, 237-257.

Petrescu, R. V. (2019r). Contributions to the Synthesis of Fixed Axle Gears by Avoiding the Interference Phenomenon. Journal of Mechatronics and Robotics, 3, 280-300.

Petrescu, R. V. (2019a). Space Probes. Journal of Mechatronics and Robotics, 3, 301-343.

Petrescu, R. V. (2019t). Presents Some Aspects and Applications of Projective Geometry. Available at SSRN 3445158.

Petrescu, R. V. (2019u). Mechanisms With Rigid Memory. Journal of Mechatronics and Robotics, 3, 431-470.

Petrescu, R. V. (2019v). Internal Combustion Engines Forces. Journal of Mechatronics and Robotics, 3, 497-520

Petrescu, R. V. V. (2020a). British Airways is Ordering up to 42 Boeing 777-9s Aeronaves to Modernize the UK Flag Carriers Long-Haul Fleet.

Petrescu, R. V. V. (2020b). Presentation of Four-stroke Engine Design Elements. Journal of Mechatronics and Robotics, 4, 15-41.

Petrescu, R. V. V. (2020c). Presents the Kinematics and Forces at a Basic Anthropomorphic Robot. Journal of Mechatronics and Robotics, 4, 42-73.

Petrescu, R. V. V. (2020d). Presents the Kinematics of a Manipulator with Three Mobilities. Journal of Mechatronics and Robotics, 4, 85-105.

Petrescu, R. V. V. (2020e). Nanobotics. Journal of Mechatronics and Robotics, 4, 136-155. 
Petrescu, R. V. V. (2020f). Mechatronic Systems to the Braking Mechanisms. Journal of Mechatronics and Robotics, 4, 156-190.

Petrescu, R. V. V. (2020g). Fishing for "16 Psyche". Journal of Aircraft and Spacecraft Technology, 4, 136-151.

Petrescu, F. I., Apicella, A., Petrescu, R. V., Kozaitis, S., Bucinell, R., Aversa, R., \& Abu-Lebdeh, T. (2016). Environmental protection through nuclear energy. American Journal of Applied Sciences, 13(9), 941-946.

Petrescu, R. V., Aversa, R., Akash, B., Bucinell, R., Corchado, J., Apicella, A., \& Petrescu, F. I. (2017a). Modern propulsions for aerospace-a review. Journal of Aircraft and Spacecraft Technology, 1(1).

Petrescu, R. V., Aversa, R., Akash, B., Bucinell, R., Corchado, J., Apicella, A., \& Petrescu, F. I. (2017b). Modern propulsions for aerospace-part II. Journal of Aircraft and Spacecraft Technology, 1(1).

Petrescu, R. V., Aversa, R., Akash, B., Bucinell, R., Corchado, J., Apicella, A., \& Petrescu, F. I. (2017c). History of aviation-a short review. Journal of Aircraft and Spacecraft Technology, 1(1).

Petrescu, R. V., Aversa, R., Akash, B., Bucinell, R., Corchado, J., Apicella, A., \& Petrescu, F. I. (2017d). Lockheed martin-a short review. Journal of Aircraft and Spacecraft Technology, 1(1).

Petrescu, R. V., Aversa, R., Akash, B., Corchado, J., Apicella, A., \& Petrescu, F. I. (2017e). Our universe. Journal of Aircraft and Spacecraft Technology, 1(2).

Petrescu, R. V., Aversa, R., Akash, B., Corchado, J., Apicella, A., \& Petrescu, F. I. (2017f). What is a UFO?. Journal of Aircraft and Spacecraft Technology, 1(2).

Petrescu, R. V., Aversa, R., Akash, B., Corchado, J., Berto, F., Mirsayar, M., ... \& Petrescu, F. I. T. (2017g). About bell helicopter FCX-001 concept aircraft-a short review. Journal of Aircraft and Spacecraft Technology, 1(2), 91-96.

Petrescu, R. V., Aversa, R., Akash, B., Corchado, J., Apicella, A., \& Petrescu, F. I. (2017h). Home at airbus. Journal of Aircraft and Spacecraft Technology, 1(2).

Petrescu, R. V., Aversa, R., Akash, B., Corchado, J., Kozaitis, S., Abu-Lebdeh, T., ... \& Petrescu, F. I. (2017i). Airlander. Journal of Aircraft and Spacecraft Technology, 1(2).

Petrescu, R. V., Aversa, R., Akash, B., Corchado, J., Berto, F., Apicella, A., \& Petrescu, F. I. (2017j). When boeing is dreaming-a review. Journal of Aircraft and Spacecraft Technology, 1(3).

Petrescu, R. V., Aversa, R., Akash, B., Corchado, J., Berto, F., Apicella, A., \& Petrescu, F. I. (2017k). About northrop grumman. Journal of Aircraft and Spacecraft Technology, 1(3).
Petrescu, R. V., Aversa, R., Akash, B., Corchado, J., Berto, F., Apicella, A., \& Petrescu, F. I. (20171). Some special aircraft. Journal of Aircraft and Spacecraft Technology, 1(3).

Petrescu, R. V., Aversa, R., Akash, B., Corchado, J., Berto, F., Apicella, A., \& Petrescu, F. I. (2017m). About helicopters. Journal of Aircraft and Spacecraft Technology, 1(3), 204-223.

Petrescu, R. V., Aversa, R., Akash, B., Berto, F., Apicella, A., \& Petrescu, F. I. (2017n). The modern flight. Journal of Aircraft and Spacecraft Technology, 1(4), 224-233.

Petrescu, R. V., Aversa, R., Akash, B., Berto, F., Apicella, A., \& Petrescu, F. I. (2017o). Sustainable energy for aerospace vessels. Journal of Aircraft and Spacecraft Technology, 1(4), 234-240.

Petrescu, R. V., Aversa, R., Akash, B., Berto, F., Apicella, A., \& Petrescu, F. I. (2017p). Unmanned helicopters. Journal of Aircraft and Spacecraft Technology, 1(4), 241-248.

Petrescu, R. V., Aversa, R., Akash, B., Berto, F., Apicella, A., \& Petrescu, F. I. (2017q). Project HARP. Journal of Aircraft and Spacecraft Technology, 1(4), 249-257.

Petrescu, R. V., Aversa, R., Akash, B., Berto, F., Apicella, A., \& Petrescu, F. I. (2017r). Presentation of Romanian Engineers who Contributed to the Development of Global Aeronautics-Part I. Journal of Aircraft and Spacecraft Technology, 1(4), 258-271.

Petrescu, R. V., Aversa, R., Akash, B., Berto, F., Apicella, A., \& Petrescu, F. I. (2017s). A first-class ticket to the planet mars, please. Journal of Aircraft and Spacecraft Technology, 1(4), 272-281.

Petrescu, R. V., Aversa, R., Li, S., Bucinell, R., Kozaitis, S., Abu-Lebdeh, T., ... \& Petrescu, F. I. (2017s). Electron dimensions. American Journal of Engineering and Applied Sciences, 10(2), 584-602.

Petrescu, R. V., Aversa, R., Kozaitis, S., Apicella, A., \& Petrescu, F. I. $(2017 \mathrm{u})$. Deuteron dimensions. American Journal of Engineering and Applied Sciences, 10(3).

Petrescu, R. V., Aversa, R., Kozaitis, S., Apicella, A., \& Petrescu, F. I. (2017v). Some proposed solutions to achieve nuclear fusion. American Journal of Engineering and Applied Sciences, 10(3).

Petrescu, R. V., Aversa, R., Kozaitis, S., Apicella, A., \& Petrescu, F. I. (2017w). Some basic reactions in nuclear fusion. American Journal of Engineering and Applied Sciences, 10(3).

Petrescu, F. I. T., Petrescu, R. V., \& Mirsayar, M. (2017x). The computer algorithm for machine equations of classical distribution. Journal of Materials and Engineering Structures «JMES», 4(4), 193-209. 
Petrescu, R. V., Aversa, R., Apicella, A., Kozaitis, S., Abu-Lebdeh, T., Akash, B., \& Petrescu, F. I. (2017y). Triton for nuclear fusion. American Journal of Engineering and Applied Sciences, 10(4).

Petrescu, R. V., Aversa, R., Akash, B., Berto, F., Apicella, A., \& Petrescu, F. I. (2017z). Forces of a 3R robot. Journal of Mechatronics and Robotics, 1(1).

Petrescu, R. V., Aversa, R., Akash, B., Berto, F., Apicella, A., \& Petrescu, F. I. (2017aa). Direct geometry and cinematic to the MP-3R systems. Journal of Mechatronics and Robotics, 1(1).

Petrescu, R. V., Aversa, R., Akash, B., Berto, F., Apicella, A., \& Petrescu, F. I. (2017ab). Dynamic elements at MP3R. Journal of Mechatronics and Robotics, 1(2), 24-37.

Petrescu, R. V., Aversa, R., Akash, B., Berto, F., Apicella, A., \& Petrescu, F. I. (2017ac). Geometry and direct kinematics to MP3R with $4 \times 4$ operators. Journal of Mechatronics and Robotics, 1(2), 38-46.

Petrescu, R. V., Aversa, R., Apicella, A., Kozaitis, S., Abu-Lebdeh, T., \& Petrescu, F. I. (2017ad). Current stage in the field of mechanisms with gears and rods. Journal of Mechatronics and Robotics, 1(2), 47-57.

Petrescu, R. V., Aversa, R., Apicella, A., Kozaitis, S., Abu-Lebdeh, T., \& Petrescu, F. I. (2017ae). Geometry and inverse kinematic at the MP3R mobile systems. Journal of Mechatronics and Robotics, 1(2), 58-65.

Petrescu, R. V., Aversa, R., Apicella, A., Kozaitis, S., Abu-Lebdeh, T., \& Petrescu, F. I. (2017af). Synthesis of optimal trajectories with functions control at the level of the kinematic drive couplings. Journal of Mechatronics and Robotics, 1(2), 66-74.

Petrescu, R. V., Aversa, R., Apicella, A., Kozaitis, S., Abu-Lebdeh, T., \& Petrescu, F. I. (2017ag). The inverse kinematics of the plane system 2-3 in a mechatronic MP2R system, by a trigonometric method. Journal of Mechatronics and Robotics, 1(2), 75-87.

Petrescu, R. V., Aversa, R., Apicella, A., Kozaitis, S., Abu-Lebdeh, T., \& Petrescu, F. I. (2017ah). Serial, anthropomorphic, spatial, mechatronic systems can be studied more simply in a plan. Journal of Mechatronics and Robotics, 1(2), 88-97.

Petrescu, R. V., Aversa, R., Apicella, A., Kozaitis, S., Abu-Lebdeh, T., \& Petrescu, F. I. (2017ai). Analysis and synthesis of mechanisms with bars and gears used in robots and manipulators. Journal of Mechatronics and Robotics, 1(2), 98-108.

Petrescu, R. V., Aversa, R., Apicella, A., Kozaitis, S., Abu-Lebdeh, T., \& Petrescu, F. I. (2017aj). Speeds and accelerations in direct kinematics to the MP3R systems. Journal of Mechatronics and Robotics, 1(2), 109-117.
Petrescu, R. V., Aversa, R., Apicella, A., Kozaitis, S., Abu-Lebdeh, T., \& Petrescu, F. I. (2017ak). Geometry and determining the positions of a plan transporter manipulator. Journal of Mechatronics and Robotics, 1(2), 118-126.

Petrescu, R. V., Aversa, R., Apicella, A., \& Petrescu, F. I. (2018a). Romanian Engineering'On the Wings of the Wind'. Journal of Aircraft and Spacecraft Technology, 2(1), 1-18.

Petrescu, R. V., Aversa, R., Apicella, A., \& Petrescu, F. I. (2018b). NASA Data used to discover eighth planet circling distant star. Journal of Aircraft and Spacecraft Technology, 2(1), 19-30.

Petrescu, R. V., Aversa, R., Apicella, A., \& Petrescu, F. I. (2018c). NASA has found the most distant black hole. Journal of Aircraft and Spacecraft Technology, 2(1), 31-39.

Petrescu, R. V., Aversa, R., Apicella, A., \& Petrescu, F. I. (2018d). Nasa selects concepts for a new mission to titan, the moon of saturn. Journal of Aircraft and Spacecraft Technology, 2(1), 40-52.

Petrescu, R. V., Aversa, R., Apicella, A., \& Petrescu, F. I. (2018e). NASA sees first in 2018 the direct proof of ozone hole recovery. Journal of Aircraft and Spacecraft Technology, 2(1), 53-64.

Petrescu, R. V., Aversa, R., Apicella, A., \& Petrescu, F. I. (2018f). An Exoplanet has Smothering Stratosphere without Water. Relly Victoria Petrescu et al./Journal of Aircraft and Spacecraft Technology, 2, 65-71.

Petrescu, R. V., Aversa, R., Apicella, A., \& Petrescu, F. I. (2018g). Structure of Buried Ice on Mars. Relly Victoria Petrescu et al./Journal of Aircraft and Spacecraft Technology, 2, 72-79.

Petrescu, N., Aversa, R., Apicella, A., \& Petrescu, F. I. (2018h). A New Exoplanet Reveals its Identity. Nicolae Petrescu et al./Journal of Aircraft and Spacecraft Technology, 2, 85-96.

Petrescu, N., Aversa, R., Apicella, A., \& Petrescu, F. I. (2018i). New Researches Examines the Wing Shapes to Reduce Vortex and Wake. Journal of Aircraft and Spacecraft Technology, 2, 97-110.

Petrescu, R. V., Aversa, R., Apicella, A., \& Petrescu, F. I. (2018j). Romanian Engineering'On the Wings of the Wind'. Journal of Aircraft and Spacecraft Technology, 2(1), 1-18.

Petrescu, R. V., Aversa, R., Apicella, A., \& Petrescu, F. I. (2018k). NASA Data used to discover eighth planet circling distant star. Journal of Aircraft and Spacecraft Technology, 2(1), 19-30.

Petrescu, R. V., Aversa, R., Apicella, A., \& Petrescu, F. I. (20181). NASA has found the most distant black hole. Journal of Aircraft and Spacecraft Technology, 2(1), 31-39. 
Petrescu, R. V., Aversa, R., Apicella, A., \& Petrescu, F. I. (2018m). Nasa selects concepts for a new mission to titan, the moon of saturn. Journal of Aircraft and Spacecraft Technology, 2(1), 40-52.

Petrescu, R. V., Aversa, R., Apicella, A., \& Petrescu, F. I. (2018n). NASA sees first in 2018 the direct proof of ozone hole recovery. Journal of Aircraft and Spacecraft Technology, 2(1), 53-64.

Petrescu, R. V., Aversa, R., Apicella, A., \& Petrescu, F. I. (20180). Modern propulsions for the aerospace industry. American Journal of Engineering and Applied Sciences, 11(2), 715-755.

Petrescu, R. V., Aversa, R., Apicella, A., Kozaitis, S., Abu-Lebdeh, T., \& Petrescu, F. I. (2018p). Inverse kinematics of a stewart platform. Journal of Mechatronics and Robotics, 2(1), 45-59.

Petrescu, R. V., Aversa, R., Apicella, A., \& Petrescu, F. I. (2018q). Total static balancing and kinetostatics of the $3 \mathrm{R}$ base cinematic Chain. Journal of Mechatronics and Robotics, 2(1), 1-13.

Petrescu, R. V., Aversa, R., Apicella, A., \& Petrescu, F. I. (2018r). Switching from flat to spatial motion to 3R mechatronic systems. Journal of Mechatronics and Robotics, 2(1), 14-22.

Petrescu, R. V., Aversa, R., Apicella, A., \& Petrescu, F. I. (2018s). The dynamics of the planar cinematic balanced chain at the plan module $3 \mathrm{R}$. Journal of Mechatronics and Robotics, 2(1), 23-34.

Petrescu, R. V., Aversa, R., Apicella, A., \& Petrescu, F. I. (2018t). Dynamic kinematics of the plan balanced chain at the planar module 3R. Journal of Mechatronics and Robotics, 2(1), 35-44.

Petrescu, R. V., Aversa, R., Apicella, A., Kozaitis, S., Abu-Lebdeh, T., \& Petrescu, F. I. (2018u). Inverse kinematics of a stewart platform. Journal of Mechatronics and Robotics, 2(1), 45-59.

Petrescu, N., Aversa, R., Apicella, A., \& Petrescu, F. I. (2018v). Something about Robots Today. Journal of Mechatronics and Robotics, 2, 85-104.

Petrescu, N., Aversa, R., Apicella, A., \& Petrescu, F. I. (2018w). Structural-Topological Synthesis of Planar Mechanisms with Rods and Wheels. Journal of Mechatronics and Robotics, 2, 105-120.

Petrescu, F. I., \& Calautit, J. K. (2016a). About nano fusion and dynamic fusion. American Journal of Applied Sciences, 13(3).

Petrescu, F. I., \& Calautit, J. K. (2016b). About the light dimensions. American Journal of Applied Sciences, 13(3).

Petrescu, R. V. V., \& Petrescu, F. I. T. (2020). About gateway. Journal of Aircraft and Spacecraft Technology. 4(1), 70-87.
Petrescu, R. V. V., Aversa, R., \& Apicella, A. (2020). Structural colour from optical phenomena caused by interference with a thin or multilayer film, photonic nanocrystals, light scattering and diffraction grating effect. Journal of Aircraft and Spacecraft Technology. 4(1), 117-143.

Rahman, Z. A. (2018). On a New Equation for the Design and Development of Space Launch Vehicles. Journal of Aircraft and Spacecraft Technology, 2(1), 80-84.

Rana, S. (2020). Improved 3D Imaging Performance of AFM. Journal of Mechatronics and Robotics, 4, 8-14.

Richmond, B. (2013). Kristian von Bengtson, Space Mission. https://www.vice.com/ro/article/4xdb5g/primamisiune-cu-pilot-pe-luna-lui-jupiter-va-fiplanificata-prin-crowdsourcing

Riman, C. F. (2018). Multi-Controlled Wheelchair for Upper Extremities Disability. Journal of Mechatronics and Robotics, 2, 121-131.

Riman, C. F. (2019). Cheap Bluetooth Solution for Smart Controlled Home Devices. Journal of Mechatronics and Robotics, 3, 589-595.

Saheed, A., Adeyinka, O. M., \& Zulikha, A. B. (2019). Access Control, Fire Prevention and Surveillance Security System. Journal of Mechatronics and Robotics, 3, 563-570.

Sharma, A., \& Kosambe, S. (2020). Trajectory optimization for first human asteroid exploration mission. Journal of Aircraft and Spacecraft Technology. 4(1), 96-116.

Svensson, F., Hasselrot, A., \& Moldanova, J. (2004). Reduced environmental impact by lowered cruise altitude for liquid hydrogen-fuelled aircraft. Aerospace Science and Technology, 8(4), 307-320.

Tumino, D. (2020). Mathematical formulation and numerical implementation of a finite element with anisotropic geometry. Journal of Aircraft and Spacecraft Technology. 4(1), 26-38.

Vladescu, I. (2020). The flying car exists. The US Air Force has successfully tested it. https://evz.ro/gatamasina-zburatoare-exista-us-air-force-a-testat-o-cusucces.html?utm_source=onesignal\&fbclid=IwAR3 WWmFTIz_DBQAAwpWIDC3zsLJFaZ5KiKJsGx7 vaiuCkx_2JTuOWn2YuSQ

Welabo, A., \& Tesfamariamr, G. (2020). Trajectory Tracking Control of UR5 Robot Manipulator Using Fuzzy Gain Scheduling Terminal Sliding Mode Controller. Journal of Mechatronics and Robotics, 4, 113-135

Welch, H., \& Mondal, S. (2019). Analysis of Magnetic Wheel Adhesion Force for Climbing Robot. Journal of Robotics and Mechatronics, 3, 534-541. 
Younes, T. M., AlKhedher, M. A., SOLIMAN, A. H., \& Al Alawin, A. (2019). Design and Implementation of Myoelectric Controlled Arm. Journal of Mechatronics and Robotics, 3(1), 552-562.

\section{Source of Figures}

\section{Fig. 1-6}

https://zizuhotel.ru/ro/rabota-

blogerom/innovacionnye-razrabotki-v-sfere-

aviastroeniya-innovacionnaya/

\section{Fig. 7}

https://upload.wikimedia.org/wikipedia/commons/4/4 0/WS_YYC_737_MAX_1.jpg

Fig. 8

https://www.boeing.com/commercial/777x/

Fig. 9

https://businessaircraft.bombardier.com/en/aircraft/gl obal-8000\#!\#bba-pdp-section-4

\section{Fig. 10}

https://en.wikipedia.org/wiki/Cobalt_Co50_Valkyrie \#/media/File:Cobalt_Co50_Valkyrie_incomplete_protot ype.jpg

\section{Fig. 11}

https://upload.wikimedia.org/wikipedia/commons/c/c

6/SkiGull_in_flight_\%28skis_deployed\%29.jpeg

\section{Fig. 12}

https://es.wikipedia.org/wiki/ICON_A5\#/media/Arch ivo:Icon_A5_in_the_water.jpg

Fig. 13

https://www.cirrusaircraft.com/aircraft/vision-jet/

Fig. 14

https://www.avweb.com/news/first-flight-for-britishsingle-seater/

\section{Fig. 15}

https://upload.wikimedia.org/wikipedia/commons/0/0 a/BA609_02.jpg

Fig. 16

https://upload.wikimedia.org/wikipedia/commons/9/9 e/Bell_augusta_convertiplano.jpg

\section{Fig. 17}

https://www.militaryaerospace.com/unmanned/article /16718602/darpa-competitors-vying-to-design-fastverticaltakeoff-aircraft-expands-to-four

Fig. 18

https://www.militaryaerospace.com/computers/article /14187192/teaming-e2d-unmanned

\section{Fig. 19}

https://www.militaryaerospace.com/sensors/article/14 187088/radar-jet-fighter-artificial-intelligence

\section{Fig. 20}

https://www.militaryaerospace.com/computers/article /14185259/artificial-intelligence-ai-unmanned-combataircraft

\section{Fig. 21}

https://playtech.ro/2020/airbus-dezvaluie-treimodele-de-avioane-alimentate-cu-hidrogen/

Fig. 22

https://robbreport.com/motors/aviation/new-aircraftrevolutionize-private-aviation-2947829/

\section{Fig. 23}

https://edition.cnn.com/style/article/nasa-mitairplane-wing/index.html

\section{Fig. 24}

https://static.playtech.ro/wpcontent/uploads/2020/11/avion-persoane-supersonic.jpg

\section{Fig. 25}

https://www.ainonline.com/aviation-news/businessaviation/2020-05-14/pipistrel-slows-uber-evtol-workadvance-other-new-aircraft

\section{Fig. 26}

https://www.thejakartapost.com/travel/2019/06/07/ne $\mathrm{w}$-fuel-efficient-aircraft-design-squeezes-passengercabin-into-v-shaped-wings.html

Fig. 27-30

https://www.youtube.com/watch?v=_npxdrn5LP0\&f eature $=$ emb_rel_end

\section{Fig. 31}

https://asiatimes.com/2020/09/us-says-it-has-tested-atop-secret-sixth-gen-fighter/

\section{Fig. 32}

https://robbreport.com/motors/aviation/samad-qstarling-vtol-aircraft-1234571738/

\section{Fig. 33}

https://www.aerospacetestinginternational.com/featur es/safety-in-aviation.html

\section{Fig. 34}

https://en.wikipedia.org/wiki/Northrop_Grumman_B21_Raider\#/media/File:Artist_Rendering_B21_Bomber_ Air_Force_Official.jpg

\section{Fig. 35}

https://billionairetoys.com/rolls-royce-hybridpowered-apus-i-5-demonstrator-aircraft/

\section{Fig. 36-38}

https://www.youtube.com/watch?v=YU3EqoUXsvY

Fig. 39

https://www.youtube.com/watch?v=ZejhDmW4A0Y

Fig. 40

https://www.wired.com/2012/01/hexplane-olivervtol/

\section{Fig. 41}

https://newatlas.com/aircraft/reaction-enginesammonia-carbon-free-aviation-fuel/

\section{Fig. 42}

https://www.voestalpine.com/blog/en/mobility/aerosp ace/all-set-for-the-future-new-aircraft-technologies-aretaking-to-the-skies/ 
Florian Ion Tiberiu Petrescu / American Journal of Engineering and Applied Sciences 2020, 13 (4): 768.802 DOI: 10.3844/ajeassp.2020.768.802

Fig. 43

https://www.theguardian.com/uknews/2018/jul/16/uk-tempest-fighter-jet-typhoonfarnborough-airshow

Fig. 44

https://inhabitat.com/eads-rethinks-the-way-planesfly-with-new-all-electric-aircraft-design/

\section{Fig. 45}

https://www.express.co.uk/travel/articles/1182994/fli ghts-plane-engine-rocket-new-york-australia-reactionengines-news

Fig. 46

https://www.b1.ro/stiri/high-tech/avionul-skylondotat-cu-cel-mai-avansat-motor-cu-reactie-ar-puteaajunge-in-spatiu-43792.html

\section{Fig. 47}

https://www.express.co.uk/travel/articles/1182994/fli ghts-plane-engine-rocket-new-york-australia-reactionengines-news

\section{Fig. 48}

https://robbreport.com/motors/aviation/business-jetair-friction-power-2905135/

Fig. 49

https://www.youtube.com/watch?v=miEwfK5VVEU Fig. 50

https://www.youtube.com/watch?v=qn2x62G5GmM 